bioRxiv preprint doi: https://doi.org/10.1101/2020.12.22.424010; this version posted December 22, 2020. The copyright holder for this preprint (which was not certified by peer review) is the author/funder, who has granted bioRxiv a license to display the preprint in perpetuity. It is made available under aCC-BY-ND 4.0 International license.

\title{
Unearthing the genes of plant-beneficial marine yeast - Wickerhamomyces anomalus strain MSD1
}

Radhesh Krishnan $\mathrm{S}^{1}$, Prabhakaran $\mathrm{N}^{1}$, Sengali Ragunath $\mathrm{K}^{1}$, Srinivasan $\mathrm{R}^{1}$, Keerthana Ponni $\mathrm{K}^{1}$, Balaji $\mathrm{G}^{1}$, Gracy M, Brindha C, Lakshmi Narayanan and Latha $\mathrm{K}^{1^{*}}$

${ }^{1} \mathrm{R} \&$ D Division Extension, T. Stanes and Company Limited, Coimbatore-641018, TN.

"Correspondence: testinglab@t-stanes.com

\section{Abstract}

The de novo genome of unique marine yeast, Wickerhamomyces anomalus isolated from seaweed along Indian coast is presented. The genome assembly was carried out using MaSurCA assembler that generated a data size $\sim 14.3 \mathrm{mb}$ from short and long reads obtained from Illumina Hiseq 4000 and GridION-X5 respectively. This assembled genome data were used for predicting genes using Augustus gene prediction tool that reported 6720 genes and proteins. The gene sequences were used to unravel the metabolic pathway analysis using KAAS database. The protein sequences were used for secondary analysis to predict the presence of signal peptides using SignalP tool, predicting protein family, domains using Pfam tool and prediction of transmembrane helices in proteins using TMHMM tool. Presence of genes involved in plant growth-promotion and regulation (PGPR) including siderophore and IAA production, iron and sulfur transformation, zinc and phosphate solubilization, nitrogen fixation, synthesis of anti-bacterial and volatile organic compound (VOCs), were assigned. Additionally, acid and alkaline phosphatases, ACC deaminases and lytic enzymes such as $\beta$ glucanases, proteases and chitinases involved in pathogen suppression, are also reported. The study elucidates comprehensive understanding of PGP attributes of MSD1 and its potential use in agriculture as bio-fertilizer / bio-stimulant.

\section{Key words}

Industrial Microorganism, Comparative genomics, Next-generation sequencing, Genome annotation, Genes, Wickerhamomyces anomalus

\section{Introduction}

Wickerhamomyces anomalus, formerly known as Pichia anomala, Hansenula anomala, Candida pelliculosa was recently assigned to the genus Wickerhamomyces based on phylogenetic analysis of gene sequences, which has caused major changes in the classification of yeasts. This species has been frequently isolated from grapes and wines. W. anomalus is a biotechnologically relevant yeast species with food, environmental, industrial, and medical applications [1].

Wickerhamomyces anomalus has many different roles in agriculture and the food industry. W. anomalus is often among the "film-forming" yeasts associated with beer spoilage [2,3], as well as the spoilage of bakery products [4]. In contrast, $W$. anomalus is among the consortium of yeasts and other microorganisms that are necessary for the fermentation of cocoa and coffee beans, which includes 
degradation of pectin from the surrounding plant tissue (Masoud and Jespersen 2006, Schwan and Wheals 2003). W. anomalus has been tested extensively for biocontrol of mold growth that develops during postharvest storage of apples and airtight-storage of grain [5,6]. As summarized by [1], $W$. anomalus can grow under conditions of extreme environmental stress, including anaerobiosis, which makes it strongly competitive with spoilage molds under storage conditions.

The yeast has been reported for its glycosidase [7], volatile organic compound production [1] and antimicrobial [8,9] properties. This species has gained considerable importance for the wine industry since it enhances the flavor of wine $[2,5]$ and produces bioethanol [10]. The current report ascertains de novo genomic DNA of the isolate confirmed as (NCBI Accession number- MF174856, Safe deposit Accession number-NAIMCC-SD-0004) that was present as an epiphyte on the seaweed Sargassum, Mandapam Beach Park, Tamil Nadu, India. Additionally, a patent has been filed for this yeast and its use in agriculture as a Plant growth promoting yeast (Indian Patent application no. 202041036012). Annotation analysis of the whole genome sequencing (WGS) leads us in prediction and identification of key genes that are responsible for the PGPR activity of the strain MSD1.

\section{Materials and methods}

The marine yeast $W$. anomalus strain MSD1 was isolated from the marine macroalgae (Sargassum sp.,) collected from Mandapam Beach Park, Rameswaram, Tamil Nadu, India [11]. MSD1 was one among the potential seaweed associated microbes (our published research [12]) possessing plant growth promoting microbe like character (Data not disclosed here).

\section{DNA Isolation, Genome Sequencing, and Assembly \& Variation Identification and Genome Diversity Analysis}

The yeast was cultured in Zobel Marine Broth (HiMedia, Mumbai, India) for $48 \mathrm{~h}$ at $30^{\circ} \mathrm{C}$ with constant shaking $(150 \mathrm{rpm})$. The high quality DNA from the sample was sequenced at Genotypic Technology Pvt Ltd. India, using Hiseq 4000 (Illumina) and GridION-X5 (Oxford Nanopore Sequencing Technology). The short reads (Illumina) and long reads (Nanopore) data were demultiplexed using bcl2fastq and guppy [13] respectively. Hybrid assembly was performed using Illumina and nanopore reads by MaSurCA Hybrid Assembler [14] with standard parameters. The gene and protein sequence prediction from the assembled genome was performed using Augustus tool [15]. The secondary analysis of the protein was carried out using different protein analytical tools (signalp, tmhmm, PfamScan) [16-18]. The metabolic pathways were predicted using KAAS database.

\section{Phylogenetic aanalysis}

Here we used genome sequence data from 17 publicly available yeast genomes representing 17 known major lineages and 2 non-yeast fungal out groups to generate phylogenetic tree. Wickerhamomyces anomalus NRRL Y-366-8 (LWUN00000000.1), Saccharomyces cerevisiae (JRIV00000000.1), Babjeviella inositovora NRRL Y-12698 (LWKO00000000.1), Suhomyces tanzawaensis NRRL Y-17324 (LYME00000000.1), Metschnikowia bicuspidata var. bicuspidata NRRL 
bioRxiv preprint doi: https://doi.org/10.1101/2020.12.22.424010; this version posted December 22, 2020. The copyright holder for this preprint (which was not certified by peer review) is the author/funder, who has granted bioRxiv a license to display the preprint in perpetuity. It is made available under aCC-BY-ND 4.0 International license.

YB-4993 (LXTC00000000.1), Hyphopichia burtonii NRRL Y-1933 (LYBQ00000000.1), Ascoidea rubescens DSM 1968 (LYBR00000000.1), Candida arabinofermentans NRRL YB-2248 (LWUO00000000.1), Tortispora caseinolytica NRRL Y-17796 (LSKT00000000.1), Cyberlindnera jadinii NRRL Y-1542 (LTAD00000000.1), Hanseniaspora valbyensis NRRL Y-1626 (LXPE00000000.1), Ogataea polymorpha (AECK00000000.1), Lipomyces starkeyi NRRL Y-11557 (LSGR00000000.1), Nadsonia fulvescens var. elongata DSM 6958 (LXPB00000000.1), Pachysolen tannophilus NRRL Y-2460 (LZCH00000000.1), Pichia membranifaciens NRRL Y-2026 (AEHA00000000.1), Saitoella complicata NRRL Y-17804 (AEUO00000000.1), Trichoderma reesei (AAIL00000000), Trichoderma harzianum (JOKZ00000000.1).

\section{Comparative Genomics}

Assembled sequence was compared with the reference sequence to know the gene re-arrangements and genome coverage. We used BRIG to have circular genome representation and Mauve to visualize the synteny between reference genome and assembled genome.

\section{Nucleotide Sequence Accession Number}

This BioProject has been deposited in GenBank under accession number PRJNA556347. The sequences obtained in this project have been deposited in the NCBI Sequence Read Archive under the accession numbers SRR10092046, and SRR9822044. https://www.ncbi.nlm.nih.gov/bioproject/PRJNA556347.

\section{Results}

\section{General genome characteristics}

A total of 6.71 million paired-end reads were generated for the marine yeast from Illumina and 0.37 million reads from Nanopore-GridION respectively. Read statistics are given in Table $\mathbf{1}$ and Table 2.

The size of assembled genome generated was $\sim 14.3 \mathrm{mb}$ having 289 contigs and the longest contig was of $\sim 0.2 \mathrm{mb}$ length. Assembly was validated using blast alignment against $\mathrm{nr}$ database (Table 3).

The assembled genome sequence was used for predicting genes and protein sequences using Augustus gene prediction tool. A total of 6720 genes and proteins were predicted in the analysis. The GO annotation of the predicted genes was completed using Uniprot database and in-house scripts. Out of 6720 genes predicted, 6658 genes were annotated and 64 genes remained unannotated (Figure 1).

\section{Comparative Genomics}

Reference based whole genome sequencing of Wickerhamomyces anomalus was carried out using reference genome available at NCBI for of Wickerhamomyces anomalous, strain- NRRL Y-366-8. More than $140 \mathrm{X}$ of sequencing coverage was achieved for the genome of approximate size 14MB. More than $99 \%$ of the reference genome was covered at $1 \mathrm{X}$ and $>93 \%$ of the reference genome was covered at $20 \mathrm{X}$ by good quality data which confirms the choice of reference and 
the sufficiency of the data for reference based WGS. The consensus sequence resulted from the analysis was compared with the reference sequence in order to know genome significant rearrangements if any (Figure 2).

Assembled sequence was compared with the reference sequence to know the gene re-arrangements and genome coverage. We used BRIG to have circular genome representation and Mauve to visualize the synteny between reference genome and assembled genome (Figure 3).

Pathway analysis the yeast genome was carried for using KAAS database that provided functional annotation of genes by BLAST comparisons against the manually curated KEGG GENES database [19]. The result contains KO (KEGG Orthology) assignments and automatically generated KEGG pathways (Supplementary file 1). The secondary analysis of protein sequences obtained from Augustus was carried out using different tools- SignalP, Pfam-Scan, TMHMM. SignalP tool predicts the presence of signal peptides and the location of their cleavage sites in proteins. A total of 521 signal peptides were predicted out of which 304 had trans-membrane segments and 217 without trans-membrane segments. Pfam-Scan tool was used to predict protein family and domains present in the predicted protein sequences. A total of 8280 pfam annotation (which includes family, domain, repeat and motif) were predicted for 6720 proteins. Out of 8280 pfam annotation 5339 contained clan (group of related protein families) information and 2941 had no clan information. TMHMM tool predicts transmembrane helices in given proteins sequences. A total of 6720 proteins used for transmembrane helix prediction, out of which 1377 proteins contained transmembrane helices and remaining 5343 proteins were without transmembrane helices (Supplementary file 2-4).

\section{Discussion}

\section{Genes identified from WGS of MSD1 related to PGPR traits}

We identified genes in the MSD1 genome attributable to the production of IAA, solubilization of minerals like phosphate and zinc, synthesis of sideropheres, acetoin and 2,3-butanediol, suppression of pathogenic fungi, resistance to oxidative stress, and ability to break down toxic compounds and other abiotic stresses.

Here, two proposed IAA biosynthesis pathways, amidase and aldehyde dehydrogenase pathways are identified in the genome of MSD1. In the indole-3acetonitrile (IAN) pathway IAN can first be converted to indole-3-acetamide (IAM) by nitrile hydratase and then IAM is converted to IAA by amidase. In the IPyA pathway indole-3-pyruvate (IPyA) is converted to indole-3-acetaldehyde (IAAld) by indolepyruvate decarboxylase and then to IAA by aldehyde dehydrogenase. All of these genes responsible for IAA synthesis were present in MSD1 genome [20]. 
Gluconic acid (GA) is recognized as one of the major organic acids in most bacteria responsible for the solubilization of mineral phosphates. The synthesis of GA is catalyzed by glucose dehydrogenase (GDH) and its co-factor pyrroloquinolone quinine (PQQ)[21-23]. Accordingly, the MSD1 genome was searched for the presence for phosphate transporter genes. Gene IDs PHO84 and PHO87 that encodes for inorganic phosphate transport were predicted. In addition, 5 genes encoding mitochondrial thiamine pyrophosphate transporters (solute carrier proteins) were also predicted in the MSD1 genome.

MSD 1 carrying the gene encoding for the synthesis of siderophore was identified. Genes encoding isochorismate domain containing protein, Gene IDs K08197 (7 copies) and K23503 (2 copies) that are annotated for siderophore-iron: $\mathrm{H}+$ symporter and sideroflexin respectively were predicted. These indicate that although strain MSD1 cannot synthesis numerous sideropheres, it can heterologously obtain siderophores produced by other soil bacteria [20,24].

The MSD1 genome was predicted for the presence of a cascade of genes for $\mathrm{Fe}$ uptake/transport. Genes like K07243 (high-affinity iron transporter), K19791 (iron transport multicopper oxidase), K12346 (metal iron transporter), K22736 (vacuolar iron transporter family protein), K15113 (solute carrier family 25), K02304 (precorrin-2 dehydrogenase/sirohydrochlorin ferrochelatase), and K01772 (protoporphyrin/coproporphyrin ferrochelatase) were annotated from MSD1 genome.

\section{The genes Associated with Plant Growth Promotion Traits}

Previous phenotypical and PGP abilities, observed in pure culture and in plant experiments under salt stress, was supported by the MSD1 genome content (Table 4). The MSD1-detailed genomic profile of their confirmed PGP abilities and other possible mechanisms involved in plant promotion were analyzed and described here. It has been reported that PGPR may produce compounds such as phenazine and 4-hydroxybenzoate which function as antibiotics and suppress plant pathogenic microbes [24]. UbiD, involved in 4-hydroxybenzoate synthesis, and $\mathrm{PhzC}-\mathrm{PhzF}$, involved in phenazine synthesis, were identified in the MSD1 genome. Moreover, a homologue of the gene coding for chitinase enzyme was identified that can potentially dissolve the cell wall of pathogenic fungal and insect pests [24]. In addition to these, the genes gabD and gabT which are responsible for the production of pest/disease inhibiting $\boldsymbol{\gamma}$-aminobutyric acid (GABA) in the genome was identified [20]. This suggests that the synthesis of the three antimicrobial compounds is a widespread pathway in MSD1.

In addition to the above PGP traits, two growth-promoting volatile organic compounds (VOCs), acetoin and butanediol, were reported to promote plant growth by stimulating root formation and increasing systemic disease resistance and drought tolerance in some other very efficient PGPR[5,25-29]. Genes encoding enzymes including acetolactate synthase and acetoin dehydrogenase (Table 1) which are involved in acetoin and butanediol synthesis, were detected in 
the genome of MSD1 [24,28,30]. Two pyruvate molecules condensed into acetolactate is catalyzed by acetolactate synthase, and which is converted to acetoin by acetolactate decarboxylase and finally acetoin is converted to 2,3butanediol catalyzed by acetoin reductase $[24,28,30]$.

\section{Nitrogen fixation}

Nitrogenase is the enzyme central to nitrogen fixation and it consists of Fe-protein encoded by nifH and MoFe-protein encoded by nifDK. Full assembly of the nitrogenase complex needs the products of at least twelve nif genes, especially for the processing of catalytic stability and nitrogenase metalloclusters (nifMZ, nifUS, and nif $\mathrm{W}$ ) and for synthesis of a particular molybdenum cofactor (MoCFC). Many microbial gene families are responsible for organic $\mathrm{N}$ decomposition, metabolism, and biosynthesis in soil. Here, five gene families directly related with $\mathrm{N}$ cycling processes were extracted and analyzed, including nao (nitroalkane oxidase), $\boldsymbol{n m o}$ (nitronate monooxygenase), gdh (glutamate dehydrogenase), ureC (urease) and GS (glutamine synthetase)[21].

MSD1 is able to grow on nitrogen-free medium (data not shown) and this indicates that the strain is able to fix atmospheric nitrogen. The MSD1 genome contains nif genes together with the NifU and nitronate genes which are the positive/negative regulatory proteins for nif genes [21].

\section{ACC Deaminase}

One of the mechanisms of PGPR to alleviate salt stress is the synthesis of the enzyme 1-aminocyclo-propane-1-carboxylate (ACC) deaminase or its homologue D-cysteine desulfhydrase encoded by acdS or dcyD, respectively. Both enzymes lower ethylene accumulation in stressed plants by cleaving ACC, an immediate precursor of ethylene in plants, to form ammonia and a-ketobutyrate. This reaction is pyridoxal phosphate dependent, and both ACC deaminase and Dcysteine desulfhydrase belong to the pyridoxal phosphate-dependent enzyme family PALP. In the MSD1 genome, neither acdS genes nor dcyD genes are present but eight CDSs containing genes encoding genes belonging to the PALP domain (Table 1) was found [24,31,32]. Of these genes, presence of Cys_K 1 and 2 for Cysteine desulfurase (KO ID: K04487, 5 copies of iscS), Tryptophan synthase beta chain $(2$ copies) and L-threonine ammonia-lyase ( 6 copies) both show lyase activity and potentially perform ammonia synthesis similarly to the enzymes encoded by acdS and dcyD[30].

\section{Genes of Central Metabolism and Cellular Processes}

Carbohydrate degradation pathways Emden-Meyerhof pathway and EntnerDoudoroff pathway for glucose, arabinose, mannose, trelose, mannitol, and the respective transport systems have been detected. All genes of the TCA cycle were present (Table 1). Exo- and polysaccharide biosynthesis and the respective transporter have been discovered (Table 4). A comprehensive list of detected genes is given in the supplementary files. 


\section{Genes putatively involved in salt tolerance}

MSD1 can grow well in $0-12 \% \mathrm{NaCl}$ (data not shown). Analysis of the genome reveals that strain MSD1 has a number of genes related to salt tolerance. For example, trehalose can act as an osmoprotectant under environmental stresses such as high salt or drought, low temperature or osmotic stress in many organisms. Trehalose accumulates in transgenic rice and enhances plant abiotic stress tolerance. So far five trehalose biosynthetic pathways have been found in bacteria including treS, otsA/otsB, treP, treT and treY/treZ40[30,33]. Here, two trehalose biosynthesis pathway otsA/B, were identified in the MSD1 genome. In the otsA/otsB pathway both glucose-6-phosphate and UDP-glucose can synthesize trehalose-6-phosphate catalyzed by trehalose-6-phosphate synthase (otsA) activity. Trehalose-6-phosphate is then formed from trehalose catalyzed by trehalose-6-phosphate phosphatase (otsB) activity. Eventually, trehalose may be hydrolyzed by trehalase (2 copies) with the generation of two glucose molecules (Table 4). This pathway has been recognized as a universal pathway present in microorganisms and contributes to the survival under harsh environmental conditions [30,33].

Moreover, a number of osmoregulation receptors and transport systems were determined in the MSD1 genome. These genes can encode up to 24 two component systems (TCSs), among which 21 TCSs can be functionally assigned based on the KEGG database (Table 4) [30,33].

Of those 21 assigned TCSs, 3 belong to the SSK1 (response regulator) family, two to the YPD1 (phosphorelay intermediate protein) family, 16 belong to the SLN1 (sensor histidine kinase) family and one to the SKN7 (response regulator) family. The eight remaining TCS genes are annotated as sensor histidine kinase (Table 4).

In addition, genes encoding transport systems such as $\mathrm{K}+$ transport systems for $\mathrm{K}+$ accumulation and $\mathrm{H}+/ \mathrm{Na}+$ antiporters (nha) for importing $\mathrm{H}+$ and pumping out $\mathrm{Na}+$ have also been found to resist hyperosmotic (Aft1 domain) stress in the genome of MSD1 (Table 4).

The MSD1 genome carries heat shock genes dnaJ, dnaK, groES, groEL, htpG, and grpE (Table 4). Moreover, the clpB gene, a heat shock protein, specified to be upregulated during salt stress in marine bacteria is also contained. The MSD1 genome also carries CDSs encoding for peroxidases, superoxidase, and glutathione S-transferase (Table $\mathbf{1}$ ). These genes play a role in the protection of cell oxidative stress caused by salt stress[30,33,34].

The genome sequence of marine isolate $W$. anomalus strain MSD1 presented in this paper is a plant growth promoting yeast isolated from the seaweed [12]. This study showed MSD1 has potential traits such as Zinc and phosphate-solubilizing, iron and sulfate transformation capability, production of ACC deaminase, siderophore, and VOCs; making it as an effective PGP yeast. Considering a variety of complex conditions that occur in rhizospheres [35], the environmental 
adaptability of PGPR in in situ rhizosphere became an important factor for improved plant growth-promoting capacity. In addition, initial studies focusing on the functional properties of PGPR have led to interest in the comparative analyses of pan-/core-genomes of these bacteria, which are of ecological importance for elucidating the fundamental genotypic features of PGPY $[36,37]$.

\section{Conclusions}

The genetic information obtained for $W$. anomalus strain MSD1 will enable us to interpret the expressed traits of the yeast and further provide insights into the practical applications of the strain as a bio-stimulant/PGPR for agriculture use or agri-input.

\section{Data availability}

This whole genome sequence of the biosample SAMN12347843 has been deposited at GenBank/NCBI under the accession number SRR10092046 and BioProject number PRJNA556347. The associated Illumina HiSeq 4000 subreads are available under the SRA accession number SRR9822044. https://www.ncbi.nlm.nih.gov/bioproject/PRJNA556347.

\section{Conflict of interest}

The authors declare that they have no known competing financial interests or personal relationships that could have appeared to influence the work reported in this paper.

\section{Acknowledgements}

The work is an outcome of the collaborative BIRAC project between T. Stanes \& Company Limited and DBT, India.

\section{References}

1. Passoth V, Fredlund E, Druvefors UÄ, et al. Biotechnology, physiology and genetics of the yeast Pichia anomala. FEMS Yeast Res. 2006; 6:3-13 2. Limtong S, Into P, Attarat P. Biocontrol of rice seedling rot disease caused by curvularia lunata and Helminthosporium oryzae by epiphytic yeasts from plant leaves. Microorganisms 2020; 8:

3. Tay ST, Lim SL, Tan HW. Growth inhibition of Candida species by

Wickerhamomyces anomalus mycocin and a lactone compound of Aureobasidium pullulans. BMC Complement. Altern. Med. 2014; 14:1-11

4. Coda R, Cassone A, Rizzello CG, et al. Antifungal activity of Wickerhamomyces anomalus and Lactobacillus plantarum during sourdough fermentation: Identification of novel compounds and long-term effect during storage of wheat bread. Appl. Environ. Microbiol. 2011; 77:3484-3492

5. Satora P, Tarko T, Sroka P, et al. The influence of Wickerhamomyces anomalus killer yeast on the fermentation and chemical composition of apple wines. FEMS Yeast Res. 2014; 14:729-740

6. Wang X, Glawe DA, Kramer E, et al. Biological Control of Botrytis cinerea : Interactions with Native Vineyard Yeasts from Washington State. Phytopathology 
bioRxiv preprint doi: https://doi.org/10.1101/2020.12.22.424010; this version posted December 22, 2020. The copyright holder for this preprint (which was not certified by peer review) is the author/funder, who has granted bioRxiv a license to display the preprint in perpetuity. It is made available under aCC-BY-ND 4.0 International license.

2018; 108:691-701

7. Padilla B, Gil J, Manzanares P. Challenges of the Non-Conventional Yeast Wickerhamomyces anomalus in Winemaking. Fermentation 2018; 4:68

8. De Ingeniis J, Raffaelli N, Ciani M, et al. Pichia anomala DBVPG 3003 Secretes a Ubiquitin-Like Protein That Has Antimicrobial Activity. Appl. Environ. Microbiol. 2009; 75:1129-1134

9. Schneider J, Rupp O, Trost E, et al. Genome sequence of Wickerhamomyces anomalus DSM 6766 reveals genetic basis of biotechnologically important antimicrobial activities. FEMS Yeast Res. 2012; 12:382-386

10. Swangkeaw J, Vichitphan S, Butzke CE, et al. The characterisation of a novelPichia anomala $\beta$-glucosidase with potentially aroma-enhancing capabilities in wine. Ann. Microbiol. 2009; 59:335-343

11. Singh RP, Reddy CRK. Seaweed-microbial interactions: Key functions of seaweed-associated bacteria. FEMS Microbiol. Ecol. 2014; 88:213-230 12. Srinivasan R, Ragunath K, Karuppiah V, et al. Isolation and screening of seaweed associated microbes for development of marine based Agri -inputs. Seaweed Res. Util. 2017; 39:8

13. Wick RR, Judd LM, Holt KE. Performance of neural network basecalling tools for Oxford Nanopore sequencing. Genome Biol. 2019; 20:129

14. Zimin A V., Marçais G, Puiu D, et al. The MaSuRCA genome assembler. Bioinformatics 2013; 29:2669-2677

15. Stanke M, Keller O, Gunduz I, et al. AUGUSTUS: ab initio prediction of alternative transcripts. Nucleic Acids Res. 2006; 34:W435-W439

16. Krogh A, Larsson B, von Heijne G, et al. Predicting transmembrane protein topology with a hidden markov model: application to complete genomes11Edited by F. Cohen. J. Mol. Biol. 2001; 305:567-580

17. Petersen TN, Brunak S, von Heijne G, et al. SignalP 4.0: discriminating signal peptides from transmembrane regions. Nat. Methods 2011; 8:785-786

18. Finn RD, Mistry J, Tate J, et al. The Pfam protein families database. Nucleic Acids Res. 2010; 38:D211-D222

19. Moriya Y, Itoh M, Okuda S, et al. KAAS: an automatic genome annotation and pathway reconstruction server. Nucleic Acids Res. 2007; 35:W182-W185 20. Luziatelli F, Ficca AG, Cardarelli M, et al. Genome sequencing of pantoea agglomerans $\mathrm{C} 1$ provides insights into molecular and genetic mechanisms of plant growth-promotion and tolerance to heavy metals. Microorganisms 2020; $8: 1-19$

21. Tsurumaru H, Okubo T, Okazaki K, et al. Metagenomic analysis of the bacterial community associated with the taproot of sugar beet. Microbes Environ. 2015; 30:63-69

22. Shrivastava M, Rajpurohit YS, Misra HS, et al. Survival of phosphatesolubilizing bacteria against DNA damaging agents. Can. J. Microbiol. 2010; 56:822-830

23. Choi O, Kim J, Kim JG, et al. Pyrroloquinoline quinone is a plant growth promotion factor produced by Pseudomonas fluorescens B16. Plant Physiol. 2008; 146:657-668

24. Gupta A, Gopal M, Thomas G V., et al. Whole genome sequencing and analysis of plant growth promoting bacteria isolated from the rhizosphere of plantation crops coconut, cocoa and arecanut. PLoS One 2014; 9:

25. Schneider J, Rupp O, Trost E, et al. Genome sequence of Wickerhamomyces anomalus DSM 6766 reveals genetic basis of biotechnologically important antimicrobial activities. FEMS Yeast Res. 2012; 12:382-386 
26. Bailly A, Weisskopf L. Mining the volatilomes of plant-associated microbiota for new biocontrol solutions. Front. Microbiol. 2017; 8:1-12 27. Gong AD, Li HP, Shen L, et al. The Shewanella algae strain YM8 produces volatiles with strong inhibition activity against Aspergillus pathogens and aflatoxins. Front. Microbiol. 2015; 6:1-12

28. Fincheira P, Quiroz A. Microbial volatiles as plant growth inducers. Microbiol. Res. 2018; 208:63-75

29. Parafati L, Vitale A, Restuccia C, et al. Performance evaluation of volatile organic compounds by antagonistic yeasts immobilized on hydrogel spheres against gray, green and blue postharvest decays. Food Microbiol. 2017; 63:191198

30. Liu W, Wang Q, Hou J, et al. Whole genome analysis of halotolerant and alkalotolerant plant growth-promoting rhizobacterium Klebsiella sp. D5A. Sci. Rep. 2016; 6:20-22

31. Khan MS, Zaidi A, Musarrat J. Phosphate solubilizing microorganisms: Principles and application of microphos technology. Phosphate Solubilizing Microorg. Princ. Appl. Microphos Technol. 2014; 32. Ma W, Sebestianova SB, Sebestian J, et al. Prevalence of 1aminocyclopropane-1-carboxylate deaminase in Rhizobium spp. Antonie van Leeuwenhoek, Int. J. Gen. Mol. Microbiol. 2003; 83:285-291 33. Suarez C, Ratering S, Hain T, et al. Complete genome sequence of the plant growth-promoting bacterium hartmannibacter diazotrophicus strain E19T. Int. J. Genomics 2019; 2019:

34. Zarei A, Brikis CJ, Bajwa VS, et al. Plant glyoxylate/succinic semialdehyde reductases: Comparative biochemical properties, function during chilling stress, and subcellular localization. Front. Plant Sci. 2017; 8:1-13

35. Berg G, Smalla K. Plant species and soil type cooperatively shape the structure and function of microbial communities in the rhizosphere. FEMS Microbiol. Ecol. 2009; 68:1-13 36. Khunnamwong P, Lertwattanasakul N, Jindamorakot S, et al. Evaluation of antagonistic activity and mechanisms of endophytic yeasts against pathogenic fungi causing economic crop diseases. Folia Microbiol. (Praha). 2020; 65:573-590 37. Kumla J, Nundaeng S, Suwannarach N, et al. Evaluation of Multifarious Plant Growth Promoting Trials of Yeast Isolated from the Soil of Assam Tea (Camellia sinensis var. assamica) Plantations in Northern Thailand. Microorganisms 2020; $8: 1168$

\section{Tables}


Table1. Illumina Read Statistics

\begin{tabular}{|l|l|}
\hline Sample & Read Count \\
\hline Total raw reads (in million) & $6713813(\operatorname{Read} 1, \operatorname{Read} 2)$ \\
\hline Total processed reads (in million) & $6417015(\operatorname{Read} 1, \operatorname{Read} 2)$ \\
\hline
\end{tabular}

Table2. Nanopore Read Statistics

\begin{tabular}{|l|l|}
\hline Parameters & Read Stat \\
\hline Reads Generated & 374070 \\
\hline Maximum Read Length & 61005 \\
\hline Minimum Read Length & 94 \\
\hline Average Read Length & 1177.6 \\
\hline Median Read Length & 2311 \\
\hline Total Reads Length & 440506966 \\
\hline Total Number of Non-ATGC Characters & 0 \\
\hline Percentage of Non-ATGC Characters & 0 \\
\hline Reads $>=100 \mathrm{bp}$ & 374067 \\
\hline Reads $>=200 \mathrm{bp}$ & 372318 \\
\hline Reads $>=500 \mathrm{bp}$ & 241259 \\
\hline Reads $>=1 \mathrm{Kbp}$ & 125627 \\
\hline Reads $>=10 \mathrm{Kbp}$ & 1861 \\
\hline N50 value & 1847 \\
\hline
\end{tabular}

Table 3. Assembly statistics

\begin{tabular}{|l|l|}
\hline Parameter & Statistical data \\
\hline Contigs Generated & 289 \\
\hline Maximum Contig Length & 275125 \\
\hline Minimum Contig Length & 3374 \\
\hline Average Contig Length & 49645.9 \\
\hline Median Contig Length & 51021 \\
\hline Total Contigs Length & 14347675 \\
\hline Total Number of Non-ATGC Characters & 0 \\
\hline Percentage of Non-ATGC Characters & 0 \\
\hline Contigs $>=1$ Kbp & 289 \\
\hline Contigs $>=10 \mathrm{Kbp}$ & 259 \\
\hline N50 value & 83236 \\
\hline
\end{tabular}

Table 4. Genes related to Plant Growth Promoting traits that are annotated to be present in Wickerhamomyces anomalus strain MSD1

\begin{tabular}{|l|l|l|}
\hline Attributes & $\begin{array}{l}\text { Gene or } \\
\text { protein ID }\end{array}$ & Gene Annotation \\
\hline $\begin{array}{l}\text { Indole-3- } \\
\text { Acetic acid }\end{array}$ & K01426 & Amidase \\
\hline & K00128 & Aldehyde dehydrogenase \\
\hline & K01568 & pyruvate decarboxylase \\
\hline
\end{tabular}


bioRxiv preprint doi: https://doi.org/10.1101/2020.12.22.424010; this version posted December $22,2020$. The copyright holder for this preprint (which was not certified by peer review) is the author/funder, who has granted bioRxiv a license to display the preprint in perpetuity. It is made available under aCC-BY-ND 4.0 International license.

\begin{tabular}{|c|c|c|}
\hline \multicolumn{3}{|c|}{ GABA production } \\
\hline$g a b D$ & g6155.t1 & $\begin{array}{l}\text { succinate-semialdehyde dehydrogenase (NAD+) activity } \\
\text { [GO:0004777]; succinate-semialdehyde dehydrogenase } \\
\text { [NAD(P)+] activity [GO:0009013]; cellular response to oxidative } \\
\text { stress [GO:0034599]; gamma-aminobutyric acid catabolic } \\
\text { process [GO:0009450]; glutamate decarboxylation to succinate } \\
\text { [GO:0006540] }\end{array}$ \\
\hline \multirow[t]{2}{*}{$g a b T$} & g4127.t1 & $\begin{array}{l}\text { cytosol [GO:0005829]; 4-aminobutyrate transaminase activity } \\
\text { [GO:0003867]; pyridoxal phosphate binding [GO:0030170]; } \\
\text { gamma-aminobutyric acid catabolic process [GO:0009450] }\end{array}$ \\
\hline & g5717.t1 & $\begin{array}{l}\text { cytosol [GO:0005829]; 4-aminobutyrate transaminase activity } \\
\text { [GO:0003867]; pyridoxal phosphate binding [GO:0030170]; } \\
\text { gamma-aminobutyric acid catabolic process [GO:0009450] }\end{array}$ \\
\hline \multicolumn{3}{|l|}{ Antimicrobial } \\
\hline Phenazine & g6439.t1 & Phenazine biosynthesis-like protein \\
\hline \multirow[t]{3}{*}{$\begin{array}{l}\text { Acetoin and } \\
2,3 \text { butanediol } \\
\text { synthesis }\end{array}$} & K01653 & Acetolactete synthase 1 \\
\hline & K01652 & Acetolactete synthase \\
\hline & K00004 & $\begin{array}{l}\text { BDH; }(\mathrm{R}, \mathrm{R}) \text {-butanediol dehydrogenase / meso-butanediol } \\
\text { dehydrogenase / diacetyl reductase [EC:1.1.1.4 1.1.1.- } \\
1.1 .1 .303]\end{array}$ \\
\hline \multirow[t]{5}{*}{ Phosphate } & K08176 & $\begin{array}{l}\text { PHO84; MFS transporter, PHS family, inorganic phosphate } \\
\text { transporter }\end{array}$ \\
\hline & K14430 & PHO87_91; phosphate transporter \\
\hline & K15108 & $\begin{array}{l}\text { SLC25A19; solute carrier family } 25 \text { (mitochondrial thiamine } \\
\text { pyrophosphate transporter), member } 19\end{array}$ \\
\hline & K14684 & $\begin{array}{l}\text { SLC25A23S; solute carrier family } 25 \text { (mitochondrial phosphate } \\
\text { transporter), member } 23 / 24 / 25 / 41\end{array}$ \\
\hline & $\mathrm{K} 15102$ & $\begin{array}{l}\text { SLC25A3; solute carrier family } 25 \text { (mitochondrial phosphate } \\
\text { transporter), member } 3\end{array}$ \\
\hline \multicolumn{3}{|c|}{ Antimicrobial compound } \\
\hline $\begin{array}{l}\text { Chitinase } \\
\text { production }\end{array}$ & K01183 & Putative chitinase II \\
\hline GABA & K00135 & succinate-semialdehyde dehydrogenase \\
\hline \multicolumn{3}{|c|}{ Other PGPR fitness conferring genes } \\
\hline & K01480 & speB; agmatinase \\
\hline & K00797 & speE; spermidine synthase \\
\hline & K00802 & SMS; spermine synthase [EC:2.5.1.22] \\
\hline \multirow[t]{4}{*}{$\begin{array}{l}\text { Resistance to } \\
\text { antifungal } \\
\text { drugs }\end{array}$} & K03327 & TC.MATE; multidrug resistance protein, MATE family \\
\hline & K08157 & $\begin{array}{l}\text { TPO1; MFS transporter, DHA1 family, multidrug resistance } \\
\text { protein }\end{array}$ \\
\hline & K08165 & $\begin{array}{l}\text { ATR1; MFS transporter, DHA2 family, multidrug resistance } \\
\text { protein }\end{array}$ \\
\hline & K08158 & $\begin{array}{l}\text { MDR1; MFS transporter, DHA1 family, multidrug resistance } \\
\text { protein }\end{array}$ \\
\hline \multicolumn{3}{|c|}{ Siderophore production (Iron homeostasis) } \\
\hline & g2983.t1 & catalytic activity [GO:0003824] \\
\hline & g4122.t1 & nicotinamidase activity [GO:0008936] \\
\hline & K08197 & ARN; MFS transporter, SIT family, siderophore-iron: $\mathrm{H}^{+}$ \\
\hline
\end{tabular}


bioRxiv preprint doi: https://doi.org/10.1101/2020.12.22.424010; this version posted December $22,2020$. The copyright holder for this preprint (which was not certified by peer review) is the author/funder, who has granted bioRxiv a license to display the preprint in perpetuity. It is made available under aCC-BY-ND 4.0 International license.

\begin{tabular}{|c|c|c|}
\hline & & symporter \\
\hline & K23503 & SFXN5; sideroflexin-5 \\
\hline \multirow[t]{8}{*}{ Fe transport } & K07243 & FTR; high-affinity iron transporter \\
\hline & K19791 & FET3_5; iron transport multicopper oxidase \\
\hline & K12346 & SMF; metal iron transporter \\
\hline & K22736 & VIT; vacuolar iron transporter family protein \\
\hline & K07243 & FTR; high-affinity iron transporter \\
\hline & K15113 & $\begin{array}{l}\text { SLC25A28_37; solute carrier family } 25 \text { (mitochondrial iron } \\
\text { transporter), member } 28 / 37\end{array}$ \\
\hline & K02304 & $\begin{array}{l}\text { MET8; precorrin-2 dehydrogenase / sirohydrochlorin } \\
\text { ferrochelatase [EC:1.3.1.76 4.99.1.4] }\end{array}$ \\
\hline & K01772 & $\begin{array}{l}\text { hemH; protoporphyrin/coproporphyrin ferrochelatase } \\
\text { [EC:4.99.1.1 4.99.1.9] }\end{array}$ \\
\hline \multirow[t]{3}{*}{$\begin{array}{l}\text { Sulfur } \\
\text { metabolism }\end{array}$} & g1937.t1 & $\begin{array}{l}\text { Sulfate adenylyltransferase (EC 2.7.7.4) (ATP-sulfurylase) } \\
\text { (Sulfate adenylate transferase) (SAT) }\end{array}$ \\
\hline & g5561.t1 & Adenylyl-sulfate kinase (EC 2.7.1.25) \\
\hline & g6660.t1 & Glutathione synthetase (GSH-S) (EC 6.3.2.3) \\
\hline \multirow[t]{6}{*}{ Potassium } & g381.t1 & Putative hydrolase of sodium-potassium ATPase alpha subunit \\
\hline & g2155.t1 & $\mathrm{K}+$ potassium transporter \\
\hline & g4374.t1 & Putative hydrolase of sodium-potassium ATPase alpha subunit \\
\hline & g139.t1 & $\begin{array}{l}\text { potassium ion transport [GO:0006813]; protein insertion into } \\
\text { mitochondrial inner membrane from matrix [GO:0032979]; } \\
\text { proton transmembrane transport [GO:1902600] }\end{array}$ \\
\hline & g1052.t1 & $\begin{array}{l}\text { cellular potassium ion homeostasis [GO:0030007]; positive } \\
\text { regulation of mitochondrial translation [GO:0070131]; } \\
\text { potassium ion transport [GO:0006813]; protein insertion into } \\
\text { mitochondrial inner membrane from matrix [GO:0032979]; } \\
\text { proton transmembrane transport [GO:1902600] }\end{array}$ \\
\hline & g1718.t1 & $\begin{array}{l}\text { potassium ion transport [GO:0006813]; protein insertion into } \\
\text { mitochondrial inner membrane from matrix [GO:0032979]; } \\
\text { proton transmembrane transport [GO:1902600] }\end{array}$ \\
\hline \multirow[t]{5}{*}{ Zinc transport } & K14709 & $\begin{array}{l}\text { SLC39A1_2_3; solute carrier family } 39 \text { (zinc transporter), } \\
\text { member } 1 / 2 / 3\end{array}$ \\
\hline & K14688 & SLC30A1; solute carrier family 30 (zinc transporter), member 1 \\
\hline & $\mathrm{K} 14713$ & SLC39A7; solute carrier family 39 (zinc transporter), member 7 \\
\hline & K07238 & TC.ZIP; zinc transporter, ZIP family \\
\hline & K14692 & $\begin{array}{l}\text { SLC30A5_7; solute carrier family } 30 \text { (zinc transporter), member } \\
5 / 7\end{array}$ \\
\hline \multicolumn{3}{|c|}{ Resistance to oxidative stress } \\
\hline \multirow[t]{2}{*}{ Peroxidase } & K00432 & gpx; glutathione peroxidase \\
\hline & K03564 & $\mathrm{BCP}$; peroxiredoxin $\mathrm{Q} / \mathrm{BCP}$ \\
\hline Catalase & K03781 & katE; catalase \\
\hline \multirow[t]{2}{*}{$\begin{array}{l}\text { superoxide } \\
\text { dismutase }\end{array}$} & K04564 & SOD2; superoxide dismutase, Fe-Mn family \\
\hline & K04565 & SOD1; superoxide dismutase, $\mathrm{Cu}-\mathrm{Zn}$ family \\
\hline $\begin{array}{l}\text { glutathione S- } \\
\text { transferase }\end{array}$ & K00799 & GST; glutathione S-transferase \\
\hline Hydroperoxide & K03386 & $\begin{array}{l}\text { PRDX2_4; peroxiredoxin (alkyl hydroperoxide reductase subunit } \\
\text { C) }\end{array}$ \\
\hline \multirow[t]{3}{*}{ Heat shock } & K03687 & GRPE; molecular chaperone GrpE \\
\hline & K03686 & dnaJ; molecular chaperone DnaJ \\
\hline & K04043 & dnaK; molecular chaperone DnaK \\
\hline
\end{tabular}


bioRxiv preprint doi: https://doi.org/10.1101/2020.12.22.424010; this version posted December $22,2020$. The copyright holder for this preprint (which was not certified by peer review) is the author/funder, who has granted bioRxiv a license to display the preprint in perpetuity. It is made available under aCC-BY-ND 4.0 International license.

\begin{tabular}{|l|l|l|}
\hline Rhodamese & K11996 & $\begin{array}{l}\text { MOCS3; adenylyltransferase and sulfurtransferase [EC:2.7.7.80 } \\
2.8 .1 .11]\end{array}$ \\
\hline & \multicolumn{3}{|c|}{} \\
\hline $\begin{array}{l}\text { Genes involved in the N cycle } \\
\text { Nitrogenase } \\
\text { complex }\end{array}$ & K04487 & iscS; cysteine desulfurase [EC:2.8.1.7] \\
\hline Genes involved in salt tolerance \\
\hline $\begin{array}{l}\text { Trehalose } \\
\text { Metabolism }\end{array}$ & K16055 & $\begin{array}{l}\text { TPS; trehalose 6-phosphate synthase/phosphatase [EC:2.4.1.15 } \\
\text { 3.1.3.12] }\end{array}$ \\
\hline & K22337 & $\begin{array}{l}\text { TSL1; trehalose 6-phosphate synthase complex regulatory } \\
\text { subunit }\end{array}$ \\
\hline & K00697 & OtsA; trehalose 6-phosphate synthase [EC:2.4.1.15 2.4.1.347] \\
\hline & K01194 & TREH; alpha, alpha-trehalase [EC:3.2.1.28] \\
\hline & Kenes involved in Na and $\mathbf{K}^{+}$transport \\
\hline & K03316 & TC.CPA1; monovalent cation:H+ antiporter, CPA1 family \\
\hline & K01507 & ppa; inorganic pyrophosphatase [EC:3.6.1.1] \\
\hline
\end{tabular}

\begin{tabular}{|c|c|c|}
\hline \multicolumn{3}{|c|}{ Genes involved in $\mathrm{pH}$ wide adaptation } \\
\hline \multirow[t]{8}{*}{ Acid expressed } & K05389 & KCNKF; potassium channel subfamily K, other eukaryote \\
\hline & K14429 & $\begin{array}{l}\text { SLC12A9; solute carrier family } 12 \text { (potassium/chloride } \\
\text { transporters), member } 9\end{array}$ \\
\hline & K13754 & $\begin{array}{l}\text { SLC24A6; solute carrier family } 24 \text { (sodium/potassium/calcium } \\
\text { exchanger), member } 6\end{array}$ \\
\hline & K04078 & groES; chaperonin GroES \\
\hline & K04077 & groEL; chaperonin GroEL \\
\hline & K04043 & dnaK; molecular chaperone DnaK \\
\hline & K03695 & clpB; ATP-dependent Clp protease ATP-binding subunit ClpB \\
\hline & K03544 & clpX; ATP-dependent Clp protease ATP-binding subunit ClpX \\
\hline \multirow[t]{8}{*}{$\begin{array}{l}\text { Alkaline } \\
\text { expressed }\end{array}$} & K07300 & chaA; $\mathrm{Ca} 2+: \mathrm{H}+$ antiporter \\
\hline & K03316 & TC.CPA1; monovalent cation: $\mathrm{H}+$ antiporter, CPA1 family \\
\hline & K23541 & TMEM165; Ca2+/H+ antiporter, TMEM165/GDT1 family \\
\hline & K03316 & TC.CPA1; monovalent cation:H+ antiporter, CPA1 family \\
\hline & K08744 & CRLS; cardiolipin synthase (CMP-forming) [EC:2.7.8.41] \\
\hline & K08744 & CRLS; cardiolipin synthase (CMP-forming) [EC:2.7.8.41] \\
\hline & K20498 & DSD1; D-serine ammonia-lyase [EC:4.3.1.18] \\
\hline & K17989 & $\begin{array}{l}\text { SDS; L-serine/L-threonine ammonia-lyase [EC:4.3.1.17 } \\
\text { 4.3.1.19] }\end{array}$ \\
\hline \multicolumn{3}{|c|}{ Resistance to heavy metals } \\
\hline Divalent & g2210.t1 & $\begin{array}{l}\text { integral component of membrane [GO:0016021]; mitochondrion } \\
\text { [GO:0005739]; pyrimidine nucleotide transmembrane } \\
\text { transporter activity [GO:0015218]; divalent metal ion transport } \\
\text { [GO:0070838]; mitochondrial genome maintenance } \\
\text { [GO:0000002]; regulation of mitochondrial membrane potential } \\
\text { [GO:0051881] }\end{array}$ \\
\hline \multirow[t]{2}{*}{ sensor kinase } & g3166.t1 & $\begin{array}{l}\text { ATP binding [GO:0005524]; phosphorelay sensor kinase activity } \\
\text { [GO:0000155] }\end{array}$ \\
\hline & g4634.t1 & $\begin{array}{l}\text { histidine phosphotransfer kinase activity [GO:0009927]; } \\
\text { osmosensor activity [GO:0005034]; phosphorelay sensor kinase } \\
\text { activity [GO:0000155] }\end{array}$ \\
\hline Arsenic & K01551 & arsA; arsenite/tail-anchored protein-transporting ATPase \\
\hline
\end{tabular}


bioRxiv preprint doi: https://doi.org/10.1101/2020.12.22.424010; this version posted December $22,2020$. The copyright holder for this preprint (which was not certified by peer review) is the author/funder, who has granted bioRxiv a license to display the preprint in perpetuity. It is made available under aCC-BY-ND 4.0 International license.

\begin{tabular}{|c|c|c|}
\hline & & {$[\mathrm{EC}: 7.3 .2 .7$ 7.3.-.--] } \\
\hline & K01551 & $\begin{array}{l}\text { arsA; arsenite/tail-anchored protein-transporting ATPase } \\
\text { [EC:7.3.2.7 7.3.-.-] }\end{array}$ \\
\hline & K03325 & ACR3; arsenite transporter \\
\hline & K03325 & ACR3; arsenite transporter \\
\hline & K03325 & ACR3; arsenite transporter \\
\hline & & \\
\hline Copper & K19791 & FET3_5; iron transport multicopper oxidase \\
\hline & K19791 & FET3_5; iron transport multicopper oxidase \\
\hline & K19791 & FET3_5; iron transport multicopper oxidase \\
\hline & K14686 & $\begin{array}{l}\text { SLC31A1; solute carrier family } 31 \text { (copper transporter), member } \\
1\end{array}$ \\
\hline & K19791 & FET3_5; iron transport multicopper oxidase \\
\hline Cobalt & g1946.t1 & $\begin{array}{l}\text { cellular cobalt ion homeostasis [GO:0006877]; cellular } \\
\text { manganese ion homeostasis [GO:0030026]; cobalt ion transport } \\
\text { [GO:0006824]; manganese ion transport [GO:0006828] }\end{array}$ \\
\hline & g3821.t1 & $\begin{array}{l}\text { cellular cobalt ion homeostasis [GO:0006877]; cellular } \\
\text { detoxification of cadmium ion [GO:0098849]; cellular zinc ion } \\
\text { homeostasis [GO:0006882]; zinc ion import into endoplasmic } \\
\text { reticulum [GO:0140209] }\end{array}$ \\
\hline Mercury & g3176.t1 & $\begin{array}{l}\text { SCF ubiquitin ligase complex [GO:0019005]; cellular response } \\
\text { to methylmercury [GO:0071406]; SCF-dependent proteasomal } \\
\text { ubiquitin-dependent protein catabolic process [GO:0031146] }\end{array}$ \\
\hline Molybdenum & g78.t1 & MoCF_biosynth, Probable molybdopterin binding domain \\
\hline & g78.t1 & MoCF_biosynth, Probable molybdopterin binding domain \\
\hline & g1469.t1 & Molybdopterin oxidoreductase \\
\hline & g1469.t1 & Molybdopterin oxidoreductase \\
\hline & g3082.t1 & MoCF_biosynth, Probable molybdopterin binding domain \\
\hline & g3845.t1 & Mob_synth_C, Molybdenum Cofactor Synthesis C \\
\hline & g4014.t1 & $\begin{array}{l}\text { Oxidored_molyb, Oxidoreductase molybdopterin binding } \\
\text { domain }\end{array}$ \\
\hline Cadmium & g269.t1 & $\begin{array}{l}\text { fungal-type vacuole membrane [GO:0000329]; integral } \\
\text { component of membrane [GO:0016021]; ATP binding } \\
\text { [GO:0005524]; ATPase activity [GO:0016887]; ATPase-coupled } \\
\text { transmembrane transporter activity [GO:0042626]; bilirubin } \\
\text { transmembrane transporter activity [GO:0015127]; cadmium } \\
\text { ion transmembrane transporter activity [GO:0015086]; vacuole } \\
\text { fusion, non-autophagic [GO:0042144] }\end{array}$ \\
\hline & g387.t1 & $\begin{array}{l}\text { mitochondrion [GO:0005739]; thioredoxin peroxidase activity } \\
\text { [GO:0008379]; cell redox homeostasis [GO:0045454]; cellular } \\
\text { response to oxidative stress [GO:0034599]; response to } \\
\text { cadmium ion [GO:0046686] }\end{array}$ \\
\hline & g859.t1 & $\begin{array}{l}\text { Cdc48p-Np14p-Vms1p AAA ATPase complex [GO:0036266]; } \\
\text { cytosol [GO:0005829]; Doa10p ubiquitin ligase complex } \\
\text { [GO:0000837]; Hrd1p ubiquitin ligase ERAD-L complex } \\
\text { [GO:0000839]; nucleus [GO:0005634]; RQC complex } \\
\text { [GO:1990112]; VCP-NPL4-UFD1 AAA ATPase complex } \\
\text { [GO:0034098]; ATP binding [GO:0005524]; ATPase activity } \\
\text { [GO:0016887]; identical protein binding [GO:0042802]; protein } \\
\text { phosphatase regulator activity [GO:0019888]; ubiquitin binding } \\
\text { [GO:0043130]; ATP metabolic process [GO:0046034]; cellular } \\
\text { protein complex disassembly [GO:0043624]; cytoplasm protein } \\
\text { quality control by the ubiquitin-proteasome system }\end{array}$ \\
\hline
\end{tabular}


bioRxiv preprint doi: https://doi.org/10.1101/2020.12.22.424010; this version posted December 22, 2020. The copyright holder for this preprint (which was not certified by peer review) is the author/funder, who has granted bioRxiv a license to display the preprint in perpetuity. It is made available under aCC-BY-ND 4.0 International license.

\begin{tabular}{|c|c|c|}
\hline & & $\begin{array}{l}\text { [GO:0071629]; endoplasmic reticulum membrane fusion } \\
\text { [GO:0016320]; ER-associated misfolded protein catabolic } \\
\text { process [GO:0071712]; mitochondria-associated ubiquitin- } \\
\text { dependent protein catabolic process [GO:0072671]; mitotic } \\
\text { spindle disassembly [GO:0051228]; negative regulation of } \\
\text { telomerase activity [GO:0051974]; nonfunctional rRNA decay } \\
\text { [GO:0070651]; nuclear protein quality control by the ubiquitin- } \\
\text { proteasome system [GO:0071630]; piecemeal microautophagy of } \\
\text { the nucleus [GO:0034727]; positive regulation of histone H2B } \\
\text { ubiquitination [GO:2001168]; positive regulation of } \\
\text { mitochondrial fusion [GO:0010636]; positive regulation of } \\
\text { protein localization to nucleus [GO:1900182]; protein transport } \\
\text { to vacuole involved in ubiquitin-dependent protein catabolic } \\
\text { process via the multivesicular body sorting pathway } \\
\text { [GO:0043328]; retrograde protein transport, ER to cytosol } \\
\text { [GO:0030970]; ribophagy [GO:0034517]; ribosome-associated } \\
\text { ubiquitin-dependent protein catabolic process [GO:1990116]; } \\
\text { SCF complex disassembly in response to cadmium stress } \\
\text { [GO:1990171]; sister chromatid biorientation [GO:0031134]; } \\
\text { stress-induced homeostatically regulated protein degradation } \\
\text { pathway [GO:0120174]; ubiquitin-dependent ERAD pathway } \\
\text { [GO:0030433] }\end{array}$ \\
\hline & g1517.t1 & $\begin{array}{l}\text { cytoplasm [GO:0005737]; adenylosuccinate synthase activity } \\
\text { [GO:0004019]; GTP binding [GO:0005525]; magnesium ion } \\
\text { binding [GO:0000287]; sulfinylpropanyl adenylate synthase } \\
\text { [GO:0061483]; 'de novo' AMP biosynthetic process } \\
\text { [GO:0044208]; cellular response to cadmium ion [GO:0071276]; } \\
\text { fumarate metabolic process [GO:0006106] }\end{array}$ \\
\hline & g2030.t1 & $\begin{array}{l}\text { integral component of membrane [GO:0016021]; plasma } \\
\text { membrane [GO:0005886]; metal ion transmembrane } \\
\text { transporter activity [GO:0046873]; solute:proton symporter } \\
\text { activity [GO:0015295]; cadmium ion transport [GO:0015691]; } \\
\text { cellular cadmium ion homeostasis [GO:0006876]; cellular } \\
\text { copper ion homeostasis [GO:0006878]; cellular manganese ion } \\
\text { homeostasis [GO:0030026]; copper ion transport [GO:0006825]; } \\
\text { iron ion transport [GO:0006826]; manganese ion transport } \\
\text { [GO:0006828] }\end{array}$ \\
\hline & g2030.t1 & $\begin{array}{l}\text { integral component of membrane [GO:0016021]; plasma } \\
\text { membrane [GO:0005886]; metal ion transmembrane } \\
\text { transporter activity [GO:0046873]; solute:proton symporter } \\
\text { activity [GO:0015295]; cadmium ion transport [GO:0015691]; } \\
\text { cellular cadmium ion homeostasis [GO:0006876]; cellular } \\
\text { copper ion homeostasis [GO:0006878]; cellular manganese ion } \\
\text { homeostasis [GO:0030026]; copper ion transport [GO:0006825]; } \\
\text { iron ion transport [GO:0006826]; manganese ion transport } \\
\text { [GO:0006828] }\end{array}$ \\
\hline & g2626.t1 & $\begin{array}{l}\text { fungal-type vacuole membrane [GO:0000329]; integral } \\
\text { component of membrane [GO:0016021]; ATP binding } \\
\text { [GO:0005524]; ATPase activity [GO:0016887]; ATPase-coupled } \\
\text { glutathione S-conjugate transmembrane transporter activity } \\
\text { [GO:0015431]; ATPase-coupled phytochelatin transmembrane } \\
\text { transporter activity [GO:0044604]; ATPase-coupled } \\
\text { transmembrane transporter activity [GO:0042626]; bilirubin } \\
\text { transmembrane transporter activity [GO:0015127]; cell redox } \\
\text { homeostasis [GO:0045454]; cellular detoxification of cadmium } \\
\text { ion [GO:0098849]; glutathione metabolic process [GO:0006749]; } \\
\text { glutathione transmembrane import into vacuole [GO:0071996]; } \\
\text { phytochelatin } 2 \text { import into vacuole [GO:0036246]; vacuole } \\
\text { fusion, non-autophagic [GO:0042144] }\end{array}$ \\
\hline & g3821.t1 & $\begin{array}{l}\text { endoplasmic reticulum membrane [GO:0005789]; fungal-type } \\
\text { vacuole membrane [GO:0000329]; integral component of }\end{array}$ \\
\hline
\end{tabular}


bioRxiv preprint doi: https://doi.org/10.1101/2020.12.22.424010; this version posted December 22, 2020. The copyright holder for this preprint (which was not certified by peer review) is the author/funder, who has granted bioRxiv a license to display the preprint in perpetuity. It is made available under aCC-BY-ND 4.0 International license.

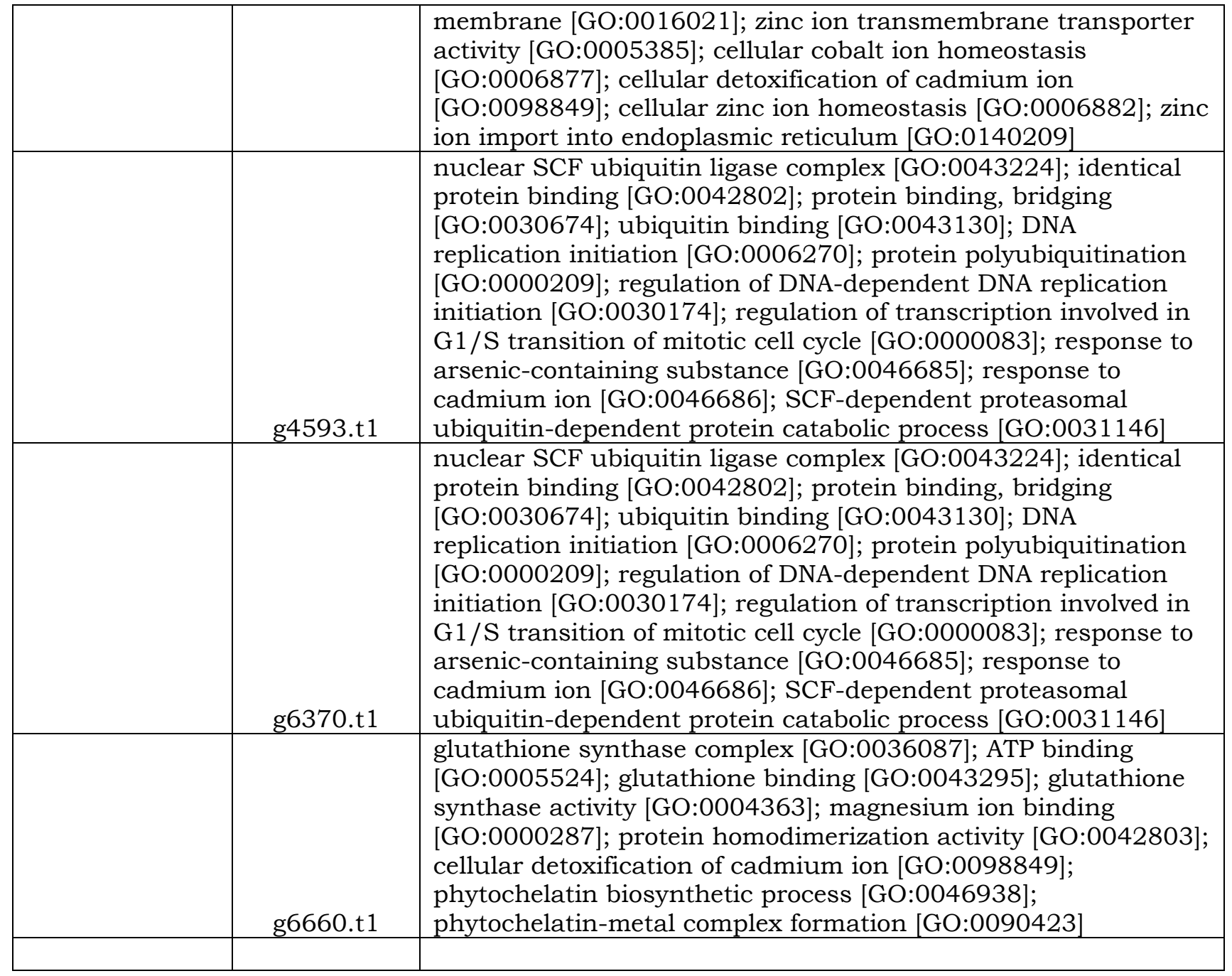

\begin{tabular}{|c|c|c|}
\hline \multicolumn{3}{|c|}{ Aromatic Compounds Degradation cleavage } \\
\hline \multirow[t]{2}{*}{ Catechol } & g3300.t1 & $\begin{array}{l}\text { catechol 1,2-dioxygenase activity [GO:0018576]; ferric iron } \\
\text { binding [GO:0008199]; catechol-containing compound } \\
\text { metabolic process [GO:0009712] }\end{array}$ \\
\hline & g3300.t1 & Catechol dioxygenase $\mathrm{N}$ terminus \\
\hline \multirow[t]{2}{*}{ Nitrilase } & g5205.t1 & $\begin{array}{l}\text { nitrilase activity [GO:0000257]; nitrogen compound metabolic } \\
\text { process [GO:0006807] }\end{array}$ \\
\hline & g6098.t1 & $\begin{array}{l}\text { nitrilase activity [GO:0000257]; nitrogen compound metabolic } \\
\text { process [GO:0006807] }\end{array}$ \\
\hline \multirow[t]{3}{*}{$\begin{array}{l}\text { Phenol } \\
\text { hydrolase }\end{array}$} & g3741.t1 & Phenol hydroxylase, C-terminal dimerisation domain \\
\hline & g5896.t1 & Phenol hydroxylase, C-terminal dimerisation domain \\
\hline & g6214.t1 & Phenol hydroxylase, C-terminal dimerisation domain \\
\hline \multirow[t]{2}{*}{ Ferridoxin } & K22071 & FDX2; ferredoxin-2, mitochondrial \\
\hline & K22071 & FDX2; ferredoxin-2, mitochondrial \\
\hline \multirow[t]{4}{*}{ Hydrolase } & g381.t1 & Putative hydrolase of sodium-potassium ATPase alpha subunit \\
\hline & g381.t1 & haloacid dehalogenase-like hydrolase \\
\hline & g4374.t1 & Putative hydrolase of sodium-potassium ATPase alpha subunit \\
\hline & g4584.t1 & Putative hydrolase of sodium-potassium ATPase alpha subunit \\
\hline
\end{tabular}


bioRxiv preprint doi: https://doi.org/10.1101/2020.12.22.424010; this version posted December 22, 2020. The copyright holder for this preprint (which was not certified by peer review) is the author/funder, who has granted bioRxiv a license to display the preprint in perpetuity. It is made available under aCC-BY-ND 4.0 International license.

\begin{tabular}{|c|c|c|}
\hline & g5107.t1 & Putative hydrolase of sodium-potassium ATPase alpha subunit \\
\hline & g6016.t1 & Putative hydrolase of sodium-potassium ATPase alpha subunit \\
\hline \multicolumn{3}{|c|}{ Biofilm formation } \\
\hline \multirow[t]{3}{*}{ Cell adhession } & g4902.t1 & $\begin{array}{l}\text { cell adhesion [GO:0007155]; cellular response to nitrogen } \\
\text { starvation [GO:0006995]; establishment of mitotic spindle } \\
\text { orientation [GO:0000132]; fungal-type cell wall assembly } \\
\text { [GO:0071940]; invasive growth in response to glucose limitation } \\
\text { [GO:0001403]; negative regulation of translation [GO:0017148]; } \\
\text { positive regulation of filamentous growth of a population of } \\
\text { unicellular organisms in response to starvation [GO:1900436]; } \\
\text { positive regulation of gluconeogenesis [GO:0045722]; positive } \\
\text { regulation of macroautophagy [GO:0016239]; positive regulation } \\
\text { of pseudohyphal growth [GO:2000222]; replicative cell aging } \\
\text { [GO:0001302]; response to unfolded protein [GO:0006986]; } \\
\text { single-species surface biofilm formation [GO:0090606] }\end{array}$ \\
\hline & g5629.t1 & $\begin{array}{l}\text { cell adhesion involved in single-species biofilm formation } \\
\text { [GO:0043709]; chromatin silencing [GO:0006342]; negative } \\
\text { regulation of chromatin silencing at rDNA [GO:0061188]; } \\
\text { negative regulation of chromatin silencing at silent mating-type } \\
\text { cassette [GO:0061186]; negative regulation of chromatin } \\
\text { silencing at telomere [GO:0031939]; negative regulation of } \\
\text { transcription by RNA polymerase II [GO:0000122]; positive } \\
\text { regulation of transcription from RNA polymerase II promoter in } \\
\text { response to heat stress [GO:0061408]; regulation of invasive } \\
\text { growth in response to glucose limitation [GO:2000217] }\end{array}$ \\
\hline & g5643.t1 & $\begin{array}{l}\text { cell adhesion involved in single-species biofilm formation } \\
\text { [GO:0043709]; chromatin silencing [GO:0006342]; negative } \\
\text { regulation of chromatin silencing at rDNA [GO:0061188]; } \\
\text { negative regulation of chromatin silencing at silent mating-type } \\
\text { cassette [GO:0061186]; negative regulation of chromatin } \\
\text { silencing at telomere [GO:0031939]; negative regulation of } \\
\text { transcription by RNA polymerase II [GO:0000122]; positive } \\
\text { regulation of transcription from RNA polymerase II promoter in } \\
\text { response to heat stress [GO:0061408]; regulation of invasive } \\
\text { growth in response to glucose limitation [GO:2000217] }\end{array}$ \\
\hline \multicolumn{3}{|l|}{ Quorum sensing } \\
\hline \multicolumn{3}{|l|}{ Homoserine } \\
\hline & K17069 & $\begin{array}{l}\text { MET17; O-acetylhomoserine/O-acetylserine sulfhydrylase } \\
{[\text { EC:2.5.1.49 2.5.1.47] }}\end{array}$ \\
\hline & K17069 & $\begin{array}{l}\text { MET17; O-acetylhomoserine/O-acetylserine sulfhydrylase } \\
\text { [EC:2.5.1.49 2.5.1.47] }\end{array}$ \\
\hline & K17069 & $\begin{array}{l}\text { MET17; O-acetylhomoserine/O-acetylserine sulfhydrylase } \\
{[\text { EC:2.5.1.49 2.5.1.47] }}\end{array}$ \\
\hline & K17069 & $\begin{array}{l}\text { MET17; O-acetylhomoserine/O-acetylserine sulfhydrylase } \\
\text { [EC:2.5.1.49 2.5.1.47] }\end{array}$ \\
\hline & K00003 & hom; homoserine dehydrogenase [EC:1.1.1.3] \\
\hline & K00003 & hom; homoserine dehydrogenase [EC:1.1.1.3] \\
\hline & K00641 & $\begin{array}{l}\text { metX; homoserine O-acetyltransferase/O-succinyltransferase } \\
\text { [EC:2.3.1.31 2.3.1.46] }\end{array}$ \\
\hline & K00641 & $\begin{array}{l}\text { metX; homoserine O-acetyltransferase/O-succinyltransferase } \\
{[\text { EC:2.3.1.31 2.3.1.46] }}\end{array}$ \\
\hline & K00872 & thrB1; homoserine kinase [EC:2.7.1.39] \\
\hline \multicolumn{3}{|c|}{ Biocontrol agents and plant growth regulators related-genes } \\
\hline & K00135 & $\begin{array}{l}\text { gabD; succinate-semialdehyde dehydrogenase / glutarate- } \\
\text { semialdehyde dehydrogenase [EC:1.2.1.16 } 1.2 .1 .79 \text { 1.2.1.20] }\end{array}$ \\
\hline & K00135 & gabD; succinate-semialdehyde dehydrogenase / glutarate- \\
\hline
\end{tabular}


bioRxiv preprint doi: https://doi.org/10.1101/2020.12.22.424010; this version posted December 22, 2020. The copyright holder for this preprint (which was not certified by peer review) is the author/funder, who has granted bioRxiv a license to display the preprint in perpetuity. It is made available under aCC-BY-ND 4.0 International license.

\begin{tabular}{|c|c|}
\hline & semialdehyde dehydrogenase [EC:1.2.1.16 1.2.1.79 1.2.1.20] \\
\hline K00135 & \begin{tabular}{|l} 
gabD; succinate-semialdehyde dehydrogenase / glutarate- \\
semialdehyde dehydrogenase [EC:1.2.1.16 1.2 .1 .79 \\
l.2.1.20]
\end{tabular} \\
\hline K00135 & $\begin{array}{l}\text { gabD; succinate-semialdehyde dehydrogenase / glutarate- } \\
\text { semialdehyde dehydrogenase [EC:1.2.1.16 1.2.1.79 } 1.2 .1 .20 \text { ] }\end{array}$ \\
\hline K00135 & \begin{tabular}{|l|l} 
gabD; succinate-semialdehyde dehydrogenase / glutarate- \\
semialdehyde dehydrogenase [EC:1.2.1.16 1.2.1.79 1.2 .1 .20$]$
\end{tabular} \\
\hline K00135 & $\begin{array}{l}\text { gabD; succinate-semialdehyde dehydrogenase / glutarate- } \\
\text { semialdehyde dehydrogenase [EC:1.2.1.16 } 1.2 .1 .79 \\
\text { l.2.1.20] }\end{array}$ \\
\hline K00135 & \begin{tabular}{|l|l} 
gabD; succinate-semialdehyde dehydrogenase / glutarate- \\
semialdehyde dehydrogenase [EC:1.2.1.16 1.2.1.79 1.2.1.20]
\end{tabular} \\
\hline K00135 & \begin{tabular}{|l|l} 
gabD; succinate-semialdehyde dehydrogenase / glutarate- \\
semialdehyde dehydrogenase [EC:1.2.1.16 1.2.1.79 1.2.1.20]
\end{tabular} \\
\hline K00135 & $\begin{array}{l}\text { gabD; succinate-semialdehyde dehydrogenase / glutarate- } \\
\text { semialdehyde dehydrogenase [EC:1.2.1.16 1.2.1.79 } 1.2 .1 .20]\end{array}$ \\
\hline K00135 & \begin{tabular}{|l|} 
gabD; succinate-semialdehyde dehydrogenase / glutarate- \\
semialdehyde dehydrogenase [EC:1.2.1.16 1.2.1.79 1.2.1.20]
\end{tabular} \\
\hline K01657 & trpE; anthranilate synthase component I [EC:4.1.3.27] \\
\hline g2983.t1 & Isochorismatase \\
\hline g4122.t1 & Isochorismatase \\
\hline g1968.t1 & $\begin{array}{l}\text { 3-hydroxyanthranilate 3,4-dioxygenase (EC 1.13.11.6) (3- } \\
\text { hydroxyanthranilate oxygenase) (3-HAO) (3-hydroxyanthranilic } \\
\text { acid dioxygenase) (HAD) (Biosynthesis of nicotinic acid protein } \\
\text { 1) }\end{array}$ \\
\hline $\begin{array}{l}\text { scf71800000 } \\
\text { 00928.g1968 } \\
\text {.t1 }\end{array}$ & 00380 Tryptophan metabolism \\
\hline
\end{tabular}

\section{Figures}

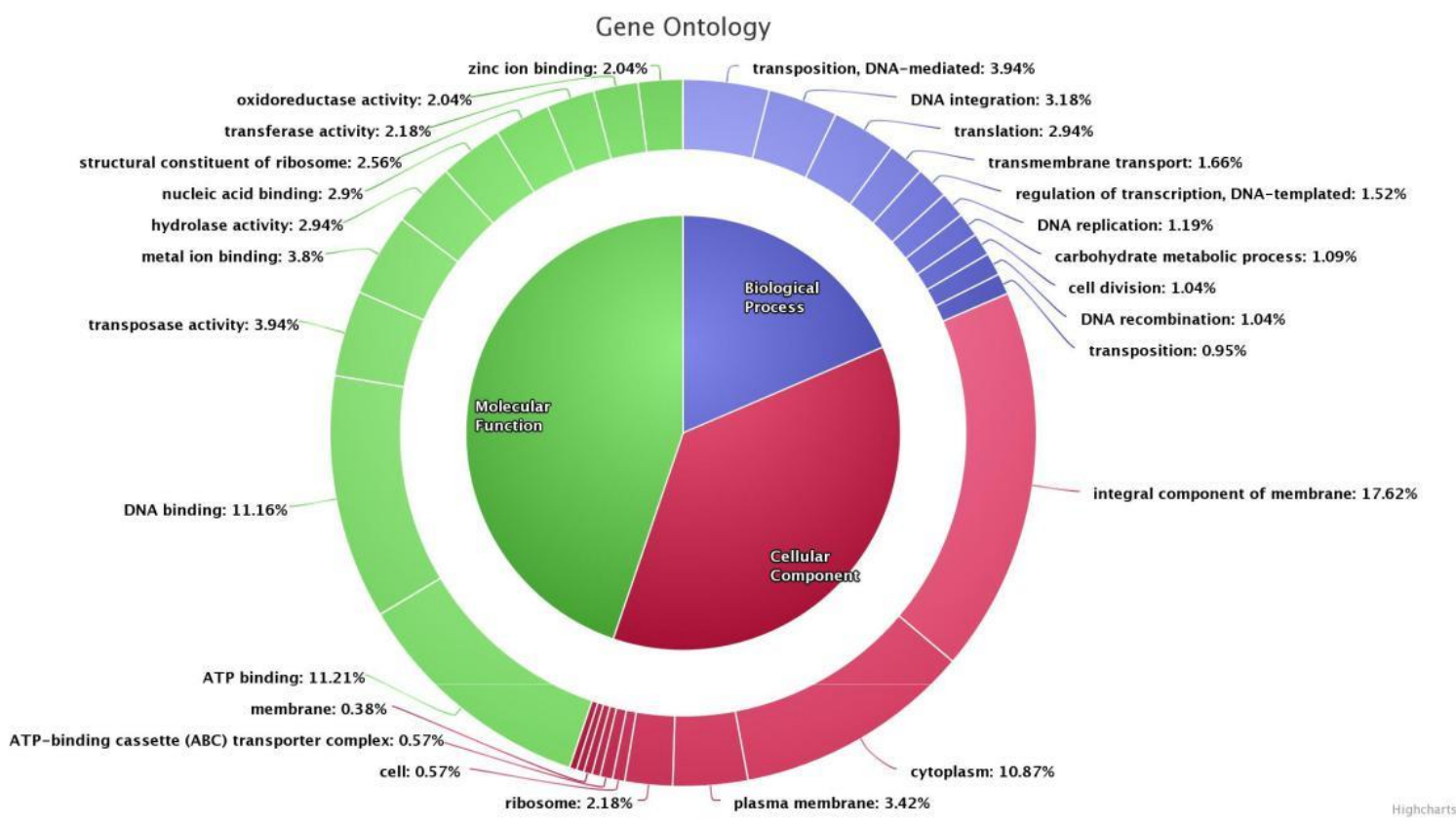

Figure 1. GO Annotation graph 
bioRxiv preprint doi: https://doi org/10.1101/2020.12.22 424010. this version posted December 22.2020. The copyriaht holder for this preprint (which was not certified by peer review) is the author/funder, who has granted bioRxiv a license to display the preprint in perpetuity. It is made available under aCC-BY-ND 4.0 International license.

496

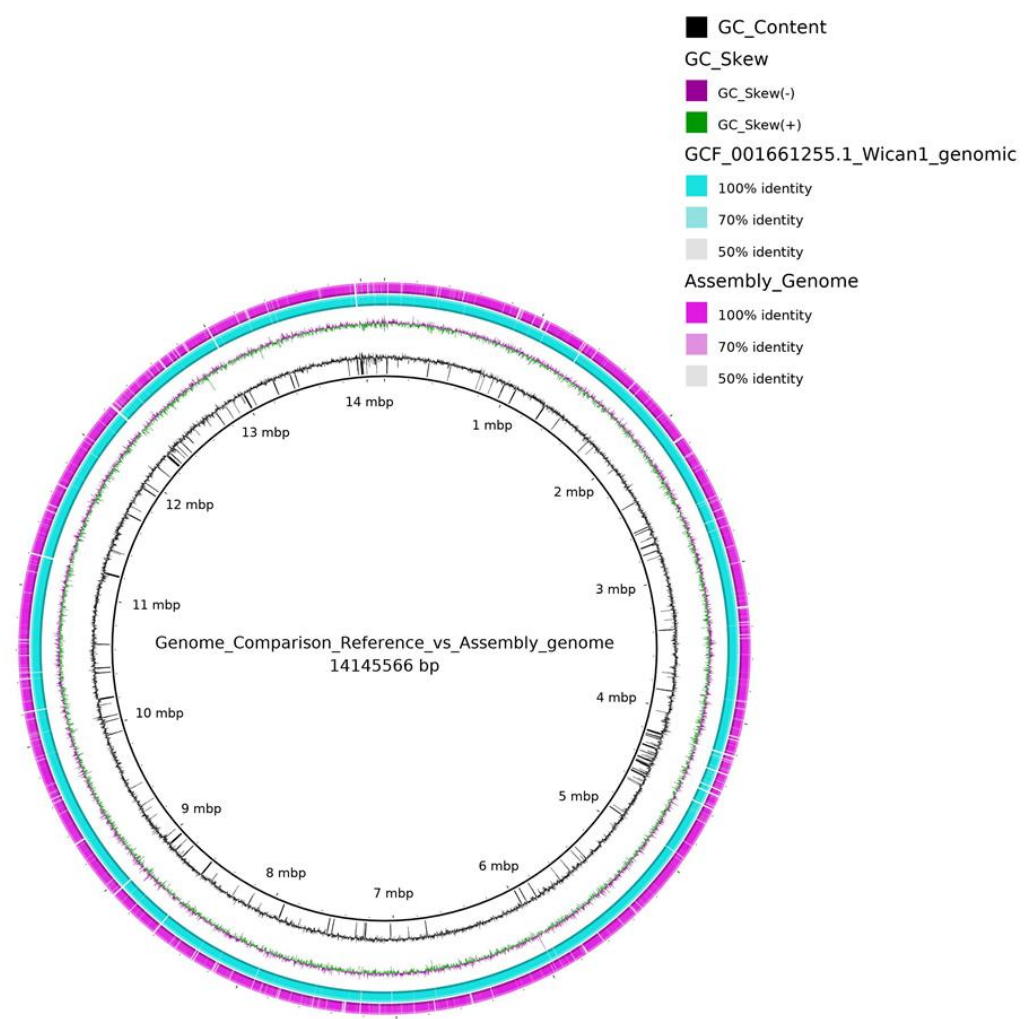

Figure 2. Genome comparison of reference (NRRL Y-366-8) and assembled genome (MSD1)
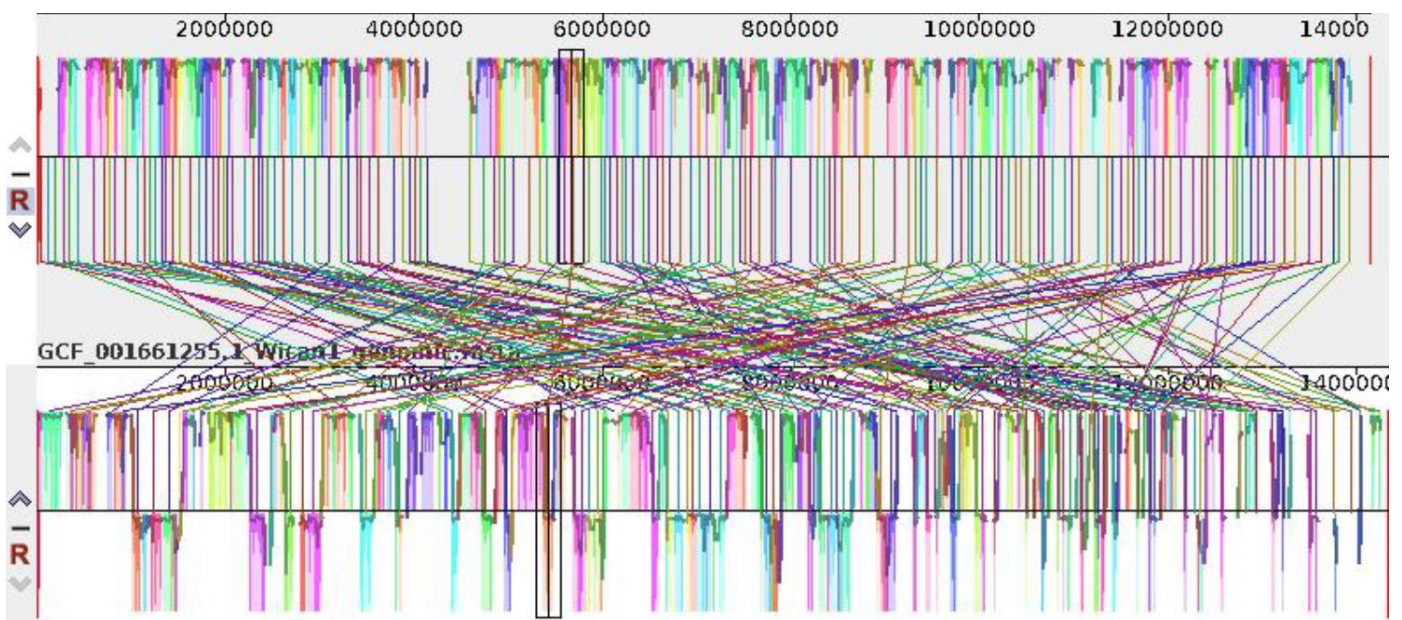

Figure 3. Synteny map of reference (NRRL Y-366-8) and assemble genome

(MSD1) 
bioRxiv preprint doi: https://doi.org/10.1101/2020.12.22.424010; this version posted December 22, 2020. The copyright holder for this preprint (which was not certified by peer review) is the author/funder, who has granted bioRxiv a license to display the preprint in perpetuity. It is made available under aCC-BY-ND 4.0 International license.

Figure 4. Phylogenetic tree visualizing the comparative genome analysis of MSD1 (Assembled genome) along with other fungal and yeast taxa.

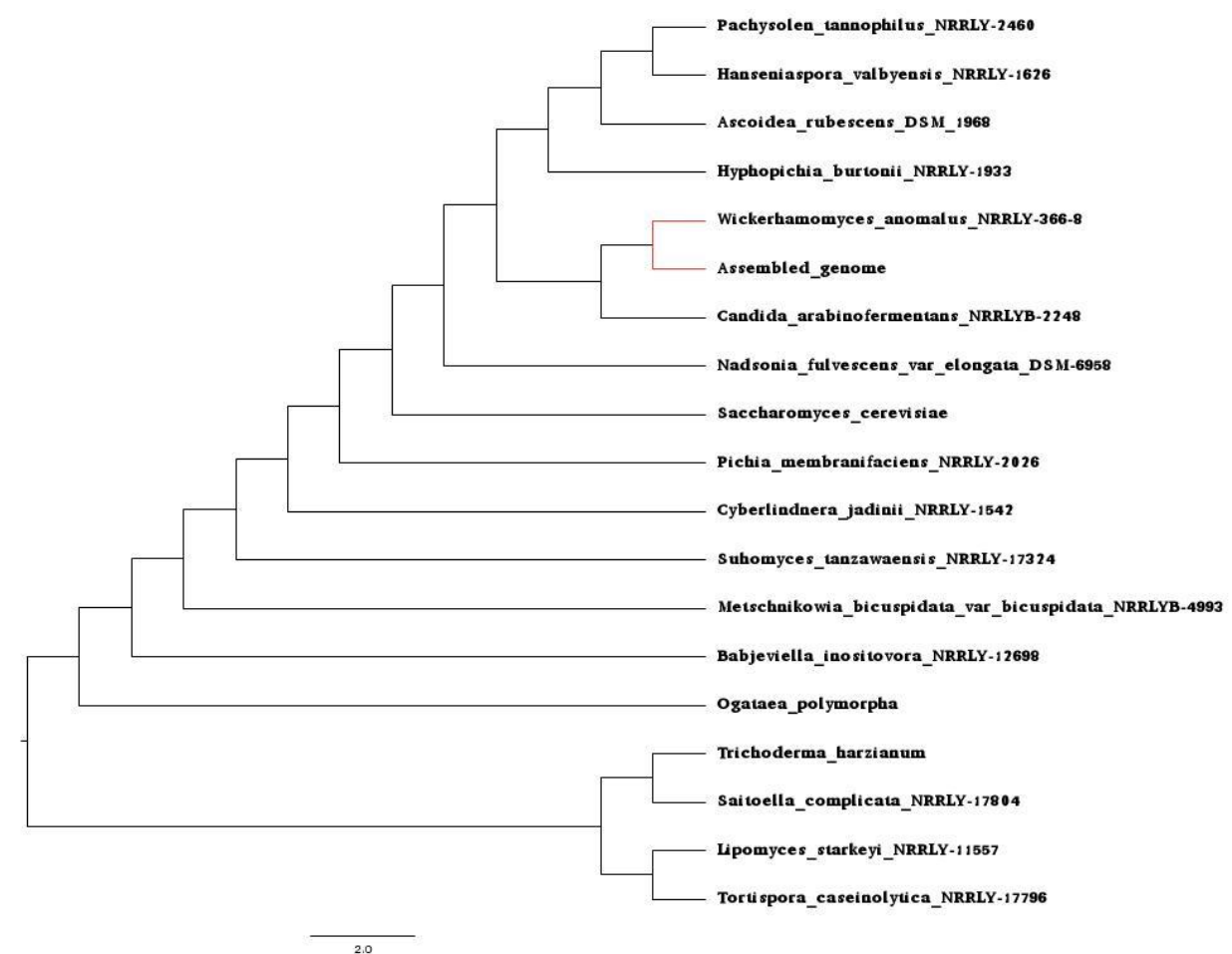


Table1. Illumina Read Statistics

\begin{tabular}{|l|l|}
\hline Sample & Read Count \\
\hline Total raw reads (in million) & $6713813(\operatorname{Read} 1, \operatorname{Read} 2)$ \\
\hline Total processed reads (in million) & $6417015(\operatorname{Read} 1, \operatorname{Read} 2)$ \\
\hline
\end{tabular}

Table2. Nanopore Read Statistics

\begin{tabular}{|l|l|}
\hline Parameters & Read Stat \\
\hline Reads Generated & 374070 \\
\hline Maximum Read Length & 61005 \\
\hline Minimum Read Length & 94 \\
\hline Average Read Length & 1177.6 \\
\hline Median Read Length & 2311 \\
\hline Total Reads Length & 440506966 \\
\hline Total Number of Non-ATGC Characters & 0 \\
\hline Percentage of Non-ATGC Characters & 0 \\
\hline Reads $>=100 \mathrm{bp}$ & 374067 \\
\hline Reads $>=200 \mathrm{bp}$ & 372318 \\
\hline Reads $>=500 \mathrm{bp}$ & 241259 \\
\hline Reads $>=1 \mathrm{Kbp}$ & 125627 \\
\hline Reads $>=10 \mathrm{Kbp}$ & 1861 \\
\hline N50 value & 1847 \\
\hline
\end{tabular}

Table 3. Assembly statistics

\begin{tabular}{|l|l|}
\hline Parameter & Statistical data \\
\hline Contigs Generated & 289 \\
\hline Maximum Contig Length & 275125 \\
\hline Minimum Contig Length & 3374 \\
\hline Average Contig Length & 49645.9 \\
\hline Median Contig Length & 51021 \\
\hline Total Contigs Length & 14347675 \\
\hline Total Number of Non-ATGC Characters & 0 \\
\hline Percentage of Non-ATGC Characters & 0 \\
\hline Contigs $>=1 \mathrm{Kbp}$ & 289 \\
\hline Contigs $>=10 \mathrm{Kbp}$ & 259 \\
\hline N50 value & 83236 \\
\hline
\end{tabular}




\begin{tabular}{|c|c|c|}
\hline & $\begin{array}{l}\text { Gene or } \\
\text { protein ID }\end{array}$ & Gene Annotation \\
\hline \multirow{3}{*}{$\begin{array}{l}\text { Indole-3- } \\
\text { Acetic acid }\end{array}$} & K01426 & Amidase \\
\hline & K00128 & Aldehyde dehydrogenase \\
\hline & K01568 & pyruvate decarboxylase \\
\hline \multicolumn{3}{|c|}{ GABA production } \\
\hline$g a b D$ & g6155.t1 & $\begin{array}{l}\text { succinate-semialdehyde dehydrogenase (NAD+) activity } \\
\text { [GO:0004777]; succinate-semialdehyde dehydrogenase } \\
\text { [NAD(P)+] activity [GO:0009013]; cellular response to } \\
\text { oxidative stress [GO:0034599]; gamma-aminobutyric acid } \\
\text { catabolic process [GO:0009450]; glutamate decarboxylation } \\
\text { to succinate [GO:0006540] }\end{array}$ \\
\hline \multirow[t]{2}{*}{$g a b T$} & g4127.t1 & $\begin{array}{l}\text { cytosol [GO:0005829]; 4-aminobutyrate transaminase } \\
\text { activity [GO:0003867]; pyridoxal phosphate binding } \\
\text { [GO:0030170]; gamma-aminobutyric acid catabolic process } \\
\text { [GO:0009450] }\end{array}$ \\
\hline & g5717.t1 & $\begin{array}{l}\text { cytosol [GO:0005829]; 4-aminobutyrate transaminase } \\
\text { activity [GO:0003867]; pyridoxal phosphate binding } \\
\text { [GO:0030170]; gamma-aminobutyric acid catabolic process } \\
\text { [GO:0009450] }\end{array}$ \\
\hline \multicolumn{3}{|c|}{ Antimicrobial } \\
\hline Phenazine & g6439.t1 & Phenazine biosynthesis-like protein \\
\hline \multirow[t]{3}{*}{$\begin{array}{l}\text { Acetoin and } \\
2,3 \\
\text { butanediol } \\
\text { synthesis }\end{array}$} & K01653 & Acetolactete synthase 1 \\
\hline & K01652 & Acetolactete synthase \\
\hline & K00004 & $\begin{array}{l}\mathrm{BDH} ;(\mathrm{R}, \mathrm{R}) \text {-butanediol dehydrogenase / meso-butanediol } \\
\text { dehydrogenase / diacetyl reductase [EC:1.1.1.4 1.1.1.- } \\
1.1 .1 .303 \text { ] }\end{array}$ \\
\hline \multirow[t]{5}{*}{ Phosphate } & K08176 & $\begin{array}{l}\text { PHO84; MFS transporter, PHS family, inorganic phosphate } \\
\text { transporter }\end{array}$ \\
\hline & K14430 & PHO87_91; phosphate transporter \\
\hline & K15108 & $\begin{array}{l}\text { SLC25A19; solute carrier family } 25 \text { (mitochondrial thiamine } \\
\text { pyrophosphate transporter), member } 19\end{array}$ \\
\hline & K14684 & $\begin{array}{l}\text { SLC25A23S; solute carrier family } 25 \text { (mitochondrial } \\
\text { phosphate transporter), member } 23 / 24 / 25 / 41\end{array}$ \\
\hline & K15102 & $\begin{array}{l}\text { SLC25A3; solute carrier family } 25 \text { (mitochondrial phosphate } \\
\text { transporter), member } 3\end{array}$ \\
\hline \multicolumn{3}{|c|}{ Antimicrobial compound } \\
\hline $\begin{array}{l}\text { Chitinase } \\
\text { production }\end{array}$ & K01183 & Putative chitinase II \\
\hline GABA & K00135 & succinate-semialdehyde dehydrogenase \\
\hline \multicolumn{3}{|c|}{ Other PGPR fitness conferring genes } \\
\hline & K01480 & speB; agmatinase \\
\hline
\end{tabular}




\begin{tabular}{|c|c|c|}
\hline & K00797 & speE; spermidine synthase \\
\hline & K00802 & SMS; spermine synthase [EC:2.5.1.22] \\
\hline \multirow[t]{4}{*}{$\begin{array}{l}\text { Resistance to } \\
\text { antifungal } \\
\text { drugs }\end{array}$} & K03327 & TC.MATE; multidrug resistance protein, MATE family \\
\hline & K08157 & $\begin{array}{l}\text { TPO1; MFS transporter, DHA1 family, multidrug resistance } \\
\text { protein }\end{array}$ \\
\hline & K08165 & $\begin{array}{l}\text { ATR1; MFS transporter, DHA2 family, multidrug resistance } \\
\text { protein }\end{array}$ \\
\hline & K08158 & $\begin{array}{l}\text { MDR1; MFS transporter, DHA1 family, multidrug resistance } \\
\text { protein }\end{array}$ \\
\hline \multicolumn{3}{|c|}{ Siderophore production (Iron homeostasis) } \\
\hline & g2983.t1 & catalytic activity [GO:0003824] \\
\hline & g4122.t1 & nicotinamidase activity [GO:0008936] \\
\hline & K08197 & $\begin{array}{l}\text { ARN; MFS transporter, SIT family, siderophore-iron:H+ } \\
\text { symporter }\end{array}$ \\
\hline & K23503 & SFXN5; sideroflexin-5 \\
\hline \multirow[t]{8}{*}{ Fe transport } & K07243 & FTR; high-affinity iron transporter \\
\hline & K19791 & FET3_5; iron transport multicopper oxidase \\
\hline & K12346 & SMF; metal iron transporter \\
\hline & K22736 & VIT; vacuolar iron transporter family protein \\
\hline & K07243 & FTR; high-affinity iron transporter \\
\hline & K15113 & $\begin{array}{l}\text { SLC25A28_37; solute carrier family } 25 \text { (mitochondrial iron } \\
\text { transporter), member } 28 / 37\end{array}$ \\
\hline & K02304 & $\begin{array}{l}\text { MET8; precorrin-2 dehydrogenase / sirohydrochlorin } \\
\text { ferrochelatase [EC:1.3.1.76 4.99.1.4] }\end{array}$ \\
\hline & K01772 & $\begin{array}{l}\text { hemH; protoporphyrin/coproporphyrin ferrochelatase } \\
\text { [EC:4.99.1.1 4.99.1.9] }\end{array}$ \\
\hline \multirow[t]{3}{*}{$\begin{array}{l}\text { Sulfur } \\
\text { metabolism }\end{array}$} & g1937.t1 & $\begin{array}{l}\text { Sulfate adenylyltransferase (EC 2.7.7.4) (ATP-sulfurylase) } \\
\text { (Sulfate adenylate transferase) (SAT) }\end{array}$ \\
\hline & g5561.t1 & Adenylyl-sulfate kinase (EC 2.7.1.25) \\
\hline & g6660.t1 & Glutathione synthetase (GSH-S) (EC 6.3.2.3) \\
\hline \multirow[t]{5}{*}{ Potassium } & g381.t1 & $\begin{array}{l}\text { Putative hydrolase of sodium-potassium ATPase alpha } \\
\text { subunit }\end{array}$ \\
\hline & g2155.t1 & $\mathrm{K}+$ potassium transporter \\
\hline & g4374.t1 & $\begin{array}{l}\text { Putative hydrolase of sodium-potassium ATPase alpha } \\
\text { subunit }\end{array}$ \\
\hline & g139.t1 & $\begin{array}{l}\text { potassium ion transport [GO:0006813]; protein insertion } \\
\text { into mitochondrial inner membrane from matrix } \\
\text { [GO:0032979]; proton transmembrane transport } \\
\text { [GO:1902600] }\end{array}$ \\
\hline & g1052.t1 & $\begin{array}{l}\text { cellular potassium ion homeostasis [GO:0030007]; positive } \\
\text { regulation of mitochondrial translation [GO:0070131]; } \\
\text { potassium ion transport [GO:0006813]; protein insertion } \\
\text { into mitochondrial inner membrane from matrix } \\
\text { [GO:0032979]; proton transmembrane transport } \\
\text { [GO:1902600] }\end{array}$ \\
\hline
\end{tabular}




\begin{tabular}{|c|c|c|}
\hline & g1718.t1 & $\begin{array}{l}\text { potassium ion transport [GO:0006813]; protein insertion } \\
\text { into mitochondrial inner membrane from matrix } \\
\text { [GO:0032979]; proton transmembrane transport } \\
\text { [GO:1902600] }\end{array}$ \\
\hline \multirow[t]{5}{*}{$\begin{array}{l}\text { Zinc } \\
\text { transport }\end{array}$} & K14709 & $\begin{array}{l}\text { SLC39A1_2_3; solute carrier family } 39 \text { (zinc transporter), } \\
\text { member } 1 / 2 / 3\end{array}$ \\
\hline & K14688 & $\begin{array}{l}\text { SLC30A1; solute carrier family } 30 \text { (zinc transporter), } \\
\text { member } 1\end{array}$ \\
\hline & K14713 & $\begin{array}{l}\text { SLC39A7; solute carrier family } 39 \text { (zinc transporter), } \\
\text { member } 7\end{array}$ \\
\hline & K07238 & TC.ZIP; zinc transporter, ZIP family \\
\hline & K14692 & $\begin{array}{l}\text { SLC30A5_7; solute carrier family } 30 \text { (zinc transporter), } \\
\text { member } 5 / 7\end{array}$ \\
\hline \multicolumn{3}{|c|}{ Resistance to oxidative stress } \\
\hline \multirow[t]{2}{*}{ Peroxidase } & K00432 & gpx; glutathione peroxidase \\
\hline & K03564 & $\mathrm{BCP}$; peroxiredoxin $\mathrm{Q} / \mathrm{BCP}$ \\
\hline Catalase & K03781 & katE; catalase \\
\hline \multirow[t]{2}{*}{$\begin{array}{l}\text { superoxide } \\
\text { dismutase }\end{array}$} & K04564 & SOD2; superoxide dismutase, Fe-Mn family \\
\hline & K04565 & SOD1; superoxide dismutase, $\mathrm{Cu}-\mathrm{Zn}$ family \\
\hline $\begin{array}{l}\text { glutathione } \\
\text { S-transferase }\end{array}$ & K00799 & GST; glutathione S-transferase \\
\hline $\begin{array}{l}\text { Hydroperoxid } \\
\text { e }\end{array}$ & K03386 & $\begin{array}{l}\text { PRDX2_4; peroxiredoxin (alkyl hydroperoxide reductase } \\
\text { subunit C) }\end{array}$ \\
\hline \multirow[t]{3}{*}{ Heat shock } & K03687 & GRPE; molecular chaperone GrpE \\
\hline & K03686 & dnaJ; molecular chaperone DnaJ \\
\hline & K04043 & dnaK; molecular chaperone DnaK \\
\hline Rhodamese & K11996 & $\begin{array}{l}\text { MOCS3; adenylyltransferase and sulfurtransferase } \\
{[\mathrm{EC}: 2.7 .7 .80 \text { 2.8.1.11] }}\end{array}$ \\
\hline \multicolumn{3}{|c|}{ Genes involved in the N cycle } \\
\hline $\begin{array}{l}\text { Nitrogenase } \\
\text { complex }\end{array}$ & K04487 & iscS; cysteine desulfurase [EC:2.8.1.7] \\
\hline \multicolumn{3}{|c|}{ Genes involved in salt tolerance } \\
\hline \multirow[t]{4}{*}{$\begin{array}{l}\text { Trehalose } \\
\text { Metabolism }\end{array}$} & K16055 & $\begin{array}{l}\text { TPS; trehalose 6-phosphate synthase/phosphatase } \\
\text { [EC:2.4.1.15 3.1.3.12] }\end{array}$ \\
\hline & K22337 & $\begin{array}{l}\text { TSL1; trehalose 6-phosphate synthase complex regulatory } \\
\text { subunit }\end{array}$ \\
\hline & K00697 & $\begin{array}{l}\text { otsA; trehalose 6-phosphate synthase [EC:2.4.1.15 } \\
\text { 2.4.1.347] }\end{array}$ \\
\hline & K01194 & TREH; alpha, alpha-trehalase [EC:3.2.1.28] \\
\hline \multicolumn{3}{|c|}{ Genes involved in $\mathrm{Na}^{+}$and $\mathrm{K}^{+}$transport } \\
\hline & K03316 & TC.CPA1; monovalent cation:H+ antiporter, CPA1 family \\
\hline & K01507 & ppa; inorganic pyrophosphatase [EC:3.6.1.1] \\
\hline
\end{tabular}




\begin{tabular}{|c|c|c|}
\hline \multicolumn{3}{|c|}{ Genes involved in pH wide adaptation } \\
\hline \multirow[t]{8}{*}{$\begin{array}{l}\text { Acid } \\
\text { expressed }\end{array}$} & K05389 & KCNKF; potassium channel subfamily K, other eukaryote \\
\hline & K14429 & $\begin{array}{l}\text { SLC12A9; solute carrier family } 12 \text { (potassium/chloride } \\
\text { transporters), member } 9\end{array}$ \\
\hline & K13754 & $\begin{array}{l}\text { SLC24A6; solute carrier family } 24 \\
\text { (sodium/potassium/calcium exchanger), member } 6\end{array}$ \\
\hline & K04078 & groES; chaperonin GroES \\
\hline & K04077 & groEL; chaperonin GroEL \\
\hline & K04043 & dnaK; molecular chaperone DnaK \\
\hline & K03695 & $\begin{array}{l}\text { clpB; ATP-dependent Clp protease ATP-binding subunit } \\
\text { ClpB }\end{array}$ \\
\hline & K03544 & $\begin{array}{l}\text { clpX; ATP-dependent Clp protease ATP-binding subunit } \\
\text { ClpX }\end{array}$ \\
\hline \multirow[t]{8}{*}{$\begin{array}{l}\text { Alkaline } \\
\text { expressed }\end{array}$} & K07300 & chaA; $\mathrm{Ca} 2+\mathrm{H}+$ antiporter \\
\hline & K03316 & TC.CPA1; monovalent cation:H+ antiporter, CPA1 family \\
\hline & K23541 & TMEM 165; Ca2+/H+ antiporter, TMEM165/GDT1 family \\
\hline & K03316 & TC.CPA1; monovalent cation:H+ antiporter, CPA1 family \\
\hline & K08744 & CRLS; cardiolipin synthase (CMP-forming) [EC:2.7.8.41] \\
\hline & K08744 & CRLS; cardiolipin synthase (CMP-forming) [EC:2.7.8.41] \\
\hline & K20498 & DSD1; D-serine ammonia-lyase [EC:4.3.1.18] \\
\hline & K17989 & $\begin{array}{l}\text { SDS; L-serine/L-threonine ammonia-lyase [EC:4.3.1.17 } \\
\text { 4.3.1.19] }\end{array}$ \\
\hline \multicolumn{3}{|c|}{ Resistance to heavy metals } \\
\hline Divalent & g2210.t1 & $\begin{array}{l}\text { integral component of membrane [GO:0016021]; } \\
\text { mitochondrion [GO:0005739]; pyrimidine nucleotide } \\
\text { transmembrane transporter activity [GO:0015218]; divalent } \\
\text { metal ion transport [GO:0070838]; mitochondrial genome } \\
\text { maintenance [GO:0000002]; regulation of mitochondrial } \\
\text { membrane potential [GO:0051881] }\end{array}$ \\
\hline \multirow[t]{2}{*}{ sensor kinase } & g3166.t1 & $\begin{array}{l}\text { ATP binding [GO:0005524]; phosphorelay sensor kinase } \\
\text { activity [GO:0000155] }\end{array}$ \\
\hline & g4634.t1 & $\begin{array}{l}\text { histidine phosphotransfer kinase activity [GO:0009927]; } \\
\text { osmosensor activity [GO:0005034]; phosphorelay sensor } \\
\text { kinase activity [GO:0000155] }\end{array}$ \\
\hline \multirow[t]{5}{*}{ Arsenic } & K01551 & $\begin{array}{l}\text { arsA; arsenite/tail-anchored protein-transporting ATPase } \\
\text { [EC:7.3.2.7 7.3.-.- }]\end{array}$ \\
\hline & K01551 & $\begin{array}{l}\text { arsA; arsenite/tail-anchored protein-transporting ATPase } \\
\text { [EC:7.3.2.7 7.3.-.- }]\end{array}$ \\
\hline & K03325 & ACR3; arsenite transporter \\
\hline & K03325 & ACR3; arsenite transporter \\
\hline & K03325 & ACR3; arsenite transporter \\
\hline \multirow{3}{*}{ Copper } & K19791 & FET3 5: iron transport multicopper \\
\hline & K19791 & FET3_5; iron transport multicopper oxidase \\
\hline & K19791 & FET3_5; iron transport multicopper oxidase \\
\hline
\end{tabular}




\begin{tabular}{|c|c|c|}
\hline & K14686 & $\begin{array}{l}\text { SLC31A1; solute carrier family } 31 \text { (copper transporter), } \\
\text { member } 1\end{array}$ \\
\hline & K19791 & FET3_5; iron transport multicopper oxidase \\
\hline \multirow[t]{2}{*}{ Cobalt } & g1946.t1 & $\begin{array}{l}\text { cellular cobalt ion homeostasis [GO:0006877]; cellular } \\
\text { manganese ion homeostasis [GO:0030026]; cobalt ion } \\
\text { transport [GO:0006824]; manganese ion transport } \\
\text { [GO:0006828] }\end{array}$ \\
\hline & g3821.t1 & $\begin{array}{l}\text { cellular cobalt ion homeostasis [GO:0006877]; cellular } \\
\text { detoxification of cadmium ion [GO:0098849]; cellular zinc } \\
\text { ion homeostasis [GO:0006882]; zinc ion import into } \\
\text { endoplasmic reticulum [GO:0140209] }\end{array}$ \\
\hline Mercury & g3176.t1 & $\begin{array}{l}\text { SCF ubiquitin ligase complex [GO:0019005]; cellular } \\
\text { response to methylmercury [GO:0071406]; SCF-dependent } \\
\text { proteasomal ubiquitin-dependent protein catabolic process } \\
\text { [GO:0031146] }\end{array}$ \\
\hline \multirow[t]{7}{*}{ Molybdenum } & g78.t1 & MoCF_biosynth, Probable molybdopterin binding domain \\
\hline & g78.t1 & MoCF_biosynth, Probable molybdopterin binding domain \\
\hline & g1469.t1 & Molybdopterin oxidoreductase \\
\hline & g1469.t1 & Molybdopterin oxidoreductase \\
\hline & g3082.t1 & MoCF_biosynth, Probable molybdopterin binding domain \\
\hline & g3845.t1 & Mob_synth_C, Molybdenum Cofactor Synthesis C \\
\hline & g4014.t1 & $\begin{array}{l}\text { Oxidored_molyb, Oxidoreductase molybdopterin binding } \\
\text { domain }\end{array}$ \\
\hline \multirow[t]{3}{*}{ Cadmium } & g269.t1 & $\begin{array}{l}\text { fungal-type vacuole membrane [GO:0000329]; integral } \\
\text { component of membrane [GO:0016021]; ATP binding } \\
\text { [GO:0005524]; ATPase activity [GO:0016887]; ATPase- } \\
\text { coupled transmembrane transporter activity [GO:0042626]; } \\
\text { bilirubin transmembrane transporter activity [GO:0015127]; } \\
\text { cadmium ion transmembrane transporter activity } \\
\text { [GO:0015086]; vacuole fusion, non-autophagic } \\
\text { [GO:0042144] }\end{array}$ \\
\hline & g387.t1 & $\begin{array}{l}\text { mitochondrion [GO:0005739]; thioredoxin peroxidase } \\
\text { activity [GO:0008379]; cell redox homeostasis } \\
\text { [GO:0045454]; cellular response to oxidative stress } \\
\text { [GO:0034599]; response to cadmium ion [GO:0046686] }\end{array}$ \\
\hline & g859.t1 & $\begin{array}{l}\text { Cdc48p-Np14p-Vms1p AAA ATPase complex [GO:0036266]; } \\
\text { cytosol [GO:0005829]; Doa10p ubiquitin ligase complex } \\
\text { [GO:0000837]; Hrd1p ubiquitin ligase ERAD-L complex } \\
\text { [GO:0000839]; nucleus [GO:0005634]; RQC complex } \\
\text { [GO:1990112]; VCP-NPL4-UFD1 AAA ATPase complex } \\
\text { [GO:0034098]; ATP binding [GO:0005524]; ATPase activity } \\
\text { [GO:0016887]; identical protein binding [GO:0042802]; } \\
\text { protein phosphatase regulator activity [GO:0019888]; } \\
\text { ubiquitin binding [GO:0043130]; ATP metabolic process } \\
\text { [GO:0046034]; cellular protein complex disassembly } \\
\text { [GO:0043624]; cytoplasm protein quality control by the } \\
\text { ubiquitin-proteasome system [GO:0071629]; endoplasmic } \\
\text { reticulum membrane fusion [GO:0016320]; ER-associated }\end{array}$ \\
\hline
\end{tabular}




\begin{tabular}{|c|c|c|}
\hline & & $\begin{array}{l}\text { misfolded protein catabolic process [GO:0071712]; } \\
\text { mitochondria-associated ubiquitin-dependent protein } \\
\text { catabolic process [GO:0072671]; mitotic spindle } \\
\text { disassembly [GO:0051228]; negative regulation of } \\
\text { telomerase activity [GO:0051974]; nonfunctional rRNA } \\
\text { decay [GO:0070651]; nuclear protein quality control by the } \\
\text { ubiquitin-proteasome system [GO:0071630]; piecemeal } \\
\text { microautophagy of the nucleus [GO:0034727]; positive } \\
\text { regulation of histone H2B ubiquitination [GO:2001168]; } \\
\text { positive regulation of mitochondrial fusion [GO:0010636]; } \\
\text { positive regulation of protein localization to nucleus } \\
\text { [GO:1900182]; protein transport to vacuole involved in } \\
\text { ubiquitin-dependent protein catabolic process via the } \\
\text { multivesicular body sorting pathway [GO:0043328]; } \\
\text { retrograde protein transport, ER to cytosol [GO:0030970]; } \\
\text { ribophagy [GO:0034517]; ribosome-associated ubiquitin- } \\
\text { dependent protein catabolic process [GO:1990116]; SCF } \\
\text { complex disassembly in response to cadmium stress } \\
\text { [GO:1990171]; sister chromatid biorientation } \\
\text { [GO:0031134]; stress-induced homeostatically regulated } \\
\text { protein degradation pathway [GO:0120174]; ubiquitin- } \\
\text { dependent ERAD pathway [GO:0030433] }\end{array}$ \\
\hline & g1517.t1 & $\begin{array}{l}\text { cytoplasm [GO:0005737]; adenylosuccinate synthase } \\
\text { activity [GO:0004019]; GTP binding [GO:0005525]; } \\
\text { magnesium ion binding [GO:0000287]; sulfinylpropanyl } \\
\text { adenylate synthase [GO:0061483]; 'de novo' AMP } \\
\text { biosynthetic process [GO:0044208]; cellular response to } \\
\text { cadmium ion [GO:0071276]; fumarate metabolic process } \\
\text { [GO:0006106] }\end{array}$ \\
\hline & g2030.t1 & $\begin{array}{l}\text { integral component of membrane [GO:0016021]; plasma } \\
\text { membrane [GO:0005886]; metal ion transmembrane } \\
\text { transporter activity [GO:0046873]; solute:proton symporter } \\
\text { activity [GO:0015295]; cadmium ion transport } \\
\text { [GO:0015691]; cellular cadmium ion homeostasis } \\
\text { [GO:0006876]; cellular copper ion homeostasis } \\
\text { [GO:0006878]; cellular manganese ion homeostasis } \\
\text { [GO:0030026]; copper ion transport [GO:0006825]; iron ion } \\
\text { transport [GO:0006826]; manganese ion transport } \\
\text { [GO:0006828] }\end{array}$ \\
\hline & g2030.t1 & $\begin{array}{l}\text { integral component of membrane [GO:0016021]; plasma } \\
\text { membrane [GO:0005886]; metal ion transmembrane } \\
\text { transporter activity [GO:0046873]; solute:proton symporter } \\
\text { activity [GO:0015295]; cadmium ion transport } \\
\text { [GO:0015691]; cellular cadmium ion homeostasis } \\
\text { [GO:0006876]; cellular copper ion homeostasis } \\
\text { [GO:0006878]; cellular manganese ion homeostasis } \\
\text { [GO:0030026]; copper ion transport [GO:0006825]; iron ion } \\
\text { transport [GO:0006826]; manganese ion transport } \\
\text { [GO:0006828] }\end{array}$ \\
\hline & g2626.t1 & $\begin{array}{l}\text { fungal-type vacuole membrane [GO:0000329]; integral } \\
\text { component of membrane [GO:0016021]; ATP binding } \\
\text { [GO:0005524]; ATPase activity [GO:0016887]; ATPase- } \\
\text { coupled glutathione S-conjugate transmembrane }\end{array}$ \\
\hline
\end{tabular}




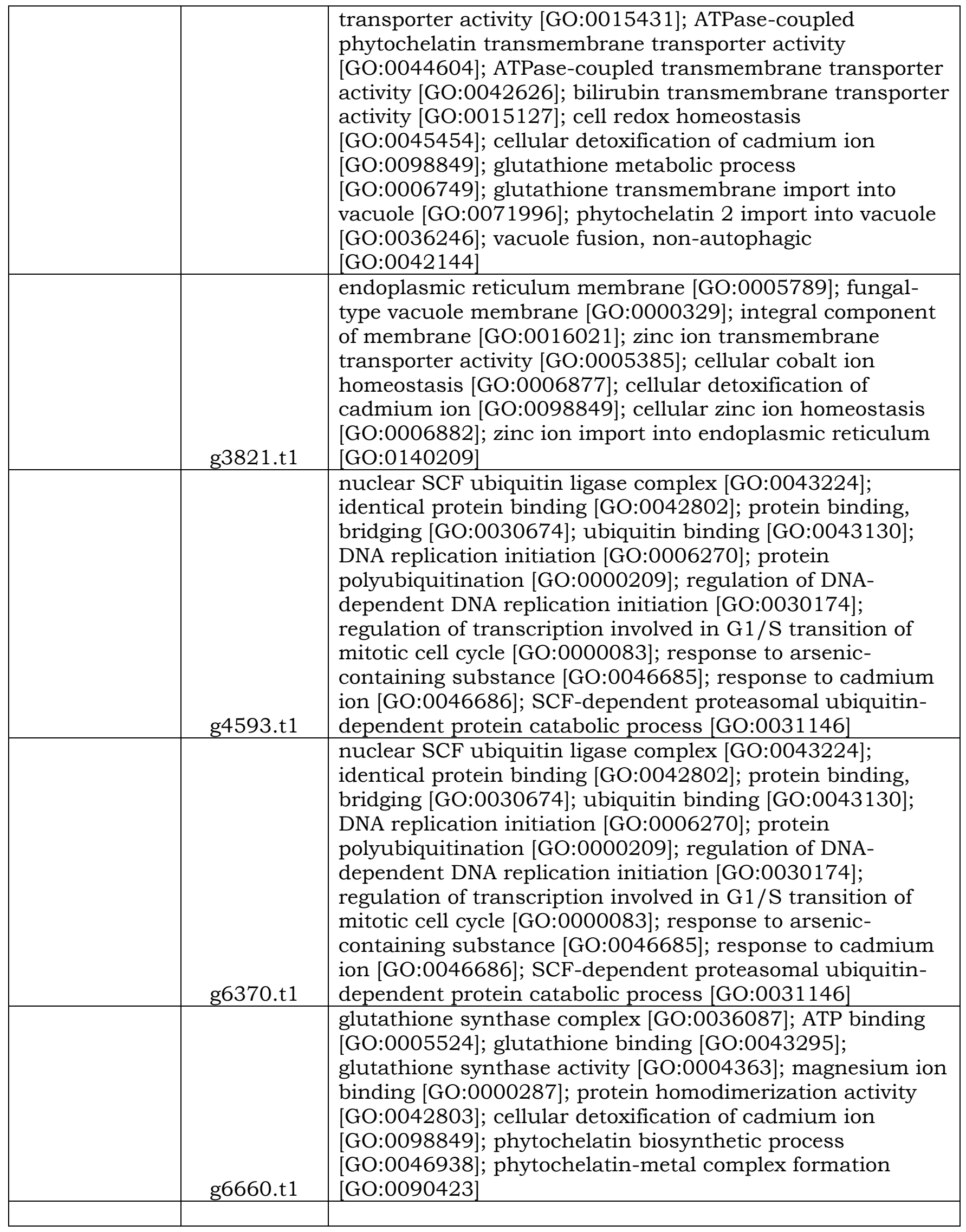




\begin{tabular}{|c|c|c|}
\hline Catechol & g3300.t1 & $\begin{array}{l}\text { catechol 1,2-dioxygenase activity [GO:0018576]; ferric iron } \\
\text { binding [GO:0008199]; catechol-containing compound } \\
\text { metabolic process [GO:0009712] }\end{array}$ \\
\hline & g3300.t1 & Catechol dioxygenase $\mathrm{N}$ terminus \\
\hline \multirow[t]{2}{*}{ Nitrilase } & g5205.t1 & $\begin{array}{l}\text { nitrilase activity [GO:0000257]; nitrogen compound } \\
\text { metabolic process [GO:0006807] }\end{array}$ \\
\hline & g6098.t1 & $\begin{array}{l}\text { nitrilase activity [GO:0000257]; nitrogen compound } \\
\text { metabolic process [GO:0006807] }\end{array}$ \\
\hline \multirow[t]{3}{*}{$\begin{array}{l}\text { Phenol } \\
\text { hydrolase }\end{array}$} & g3741.t1 & Phenol hydroxylase, C-terminal dimerisation domain \\
\hline & g5896.t1 & Phenol hydroxylase, C-terminal dimerisation domain \\
\hline & g6214.t1 & Phenol hydroxylase, C-terminal dimerisation domain \\
\hline \multirow{2}{*}{ Ferridoxin } & K22071 & FDX2; ferredoxin-2, mitochondrial \\
\hline & K22071 & FDX2; ferredoxin-2, mitochondrial \\
\hline \multirow[t]{6}{*}{ Hydrolase } & g381.t1 & $\begin{array}{l}\text { Putative hydrolase of sodium-potassium ATPase alpha } \\
\text { subunit }\end{array}$ \\
\hline & g381.t1 & haloacid dehalogenase-like hydrolase \\
\hline & g4374.t1 & $\begin{array}{l}\text { Putative hydrolase of sodium-potassium ATPase alpha } \\
\text { subunit }\end{array}$ \\
\hline & g4584.t1 & $\begin{array}{l}\begin{array}{l}\text { Putative hydrolase of sodium-potassium ATPase alpha } \\
\text { subunit }\end{array} \\
\end{array}$ \\
\hline & g5107.t1 & $\begin{array}{l}\begin{array}{l}\text { Putative hydrolase of sodium-potassium ATPase alpha } \\
\text { subunit }\end{array} \\
\end{array}$ \\
\hline & g6016.t1 & $\begin{array}{l}\text { Putative hydrolase of sodium-potassium ATPase alpha } \\
\text { subunit }\end{array}$ \\
\hline \multicolumn{3}{|c|}{ Biofilm formation } \\
\hline \multirow[t]{2}{*}{$\begin{array}{l}\text { Cell } \\
\text { adhession }\end{array}$} & g4902.t1 & $\begin{array}{l}\text { cell adhesion [GO:0007155]; cellular response to nitrogen } \\
\text { starvation [GO:0006995]; establishment of mitotic spindle } \\
\text { orientation [GO:0000132]; fungal-type cell wall assembly } \\
\text { [GO:0071940]; invasive growth in response to glucose } \\
\text { limitation [GO:0001403]; negative regulation of translation } \\
\text { [GO:0017148]; positive regulation of filamentous growth of } \\
\text { a population of unicellular organisms in response to } \\
\text { starvation [GO:1900436]; positive regulation of } \\
\text { gluconeogenesis [GO:0045722]; positive regulation of } \\
\text { macroautophagy [GO:0016239]; positive regulation of } \\
\text { pseudohyphal growth [GO:2000222]; replicative cell aging } \\
\text { [GO:0001302]; response to unfolded protein [GO:0006986]; } \\
\text { single-species surface biofilm formation [GO:0090606] }\end{array}$ \\
\hline & g5629.t1 & $\begin{array}{l}\text { cell adhesion involved in single-species biofilm formation } \\
\text { [GO:0043709]; chromatin silencing [GO:0006342]; negative } \\
\text { regulation of chromatin silencing at rDNA [GO:0061188]; } \\
\text { negative regulation of chromatin silencing at silent mating- } \\
\text { type cassette [GO:0061186]; negative regulation of } \\
\text { chromatin silencing at telomere [GO:0031939]; negative } \\
\text { regulation of transcription by RNA polymerase II }\end{array}$ \\
\hline
\end{tabular}




\begin{tabular}{|c|c|c|}
\hline & & $\begin{array}{l}\text { [GO:0000122]; positive regulation of transcription from RNA } \\
\text { polymerase II promoter in response to heat stress } \\
\text { [GO:0061408]; regulation of invasive growth in response to } \\
\text { glucose limitation [GO:2000217] }\end{array}$ \\
\hline & g5643.t1 & $\begin{array}{l}\text { cell adhesion involved in single-species biofilm formation } \\
\text { [GO:0043709]; chromatin silencing [GO:0006342]; negative } \\
\text { regulation of chromatin silencing at rDNA [GO:0061188]; } \\
\text { negative regulation of chromatin silencing at silent mating- } \\
\text { type cassette [GO:0061186]; negative regulation of } \\
\text { chromatin silencing at telomere [GO:0031939]; negative } \\
\text { regulation of transcription by RNA polymerase II } \\
\text { [GO:0000122]; positive regulation of transcription from RNA } \\
\text { polymerase II promoter in response to heat stress } \\
\text { [GO:0061408]; regulation of invasive growth in response to } \\
\text { glucose limitation [GO:2000217] }\end{array}$ \\
\hline \multicolumn{3}{|c|}{ Quorum sensing } \\
\hline \multicolumn{3}{|l|}{ Homoserine } \\
\hline & K17069 & $\begin{array}{l}\text { MET17; O-acetylhomoserine/O-acetylserine sulfhydrylase } \\
\text { [EC:2.5.1.49 2.5.1.47] }\end{array}$ \\
\hline & K17069 & $\begin{array}{l}\text { MET17; O-acetylhomoserine/O-acetylserine sulfhydrylase } \\
{[\text { EC:2.5.1.49 2.5.1.47] }}\end{array}$ \\
\hline & K17069 & $\begin{array}{l}\text { MET17; O-acetylhomoserine/O-acetylserine sulfhydrylase } \\
{[\text { EC:2.5.1.49 2.5.1.47] }}\end{array}$ \\
\hline & K17069 & $\begin{array}{l}\text { MET17; O-acetylhomoserine/O-acetylserine sulfhydrylase } \\
{[\text { [EC:2.5.1.49 2.5.1.47] }}\end{array}$ \\
\hline & K00003 & hom; homoserine dehydrogenase [EC:1.1.1.3] \\
\hline & K00003 & hom; homoserine dehydrogenase [EC:1.1.1.3] \\
\hline & K00641 & $\begin{array}{l}\text { metX; homoserine O-acetyltransferase/O- } \\
\text { succinyltransferase [EC:2.3.1.31 2.3.1.46] }\end{array}$ \\
\hline & K00641 & $\begin{array}{l}\text { metX; homoserine O-acetyltransferase/O- } \\
\text { succinyltransferase [EC:2.3.1.31 2.3.1.46] }\end{array}$ \\
\hline & K00872 & thrB1; homoserine kinase [EC:2.7.1.39] \\
\hline \multicolumn{3}{|c|}{ Biocontrol agents and plant growth regulators related-genes } \\
\hline & K00135 & $\begin{array}{l}\text { gabD; succinate-semialdehyde dehydrogenase / glutarate- } \\
\text { semialdehyde dehydrogenase [EC:1.2.1.16 1.2.1.79 } \\
1.2 .1 .20 \text { ] }\end{array}$ \\
\hline & K00135 & $\begin{array}{l}\text { gabD; succinate-semialdehyde dehydrogenase / glutarate- } \\
\text { semialdehyde dehydrogenase [EC:1.2.1.16 1.2.1.79 } \\
1.2 .1 .20 \text { ] }\end{array}$ \\
\hline & K00135 & $\begin{array}{l}\text { gabD; succinate-semialdehyde dehydrogenase / glutarate- } \\
\text { semialdehyde dehydrogenase [EC:1.2.1.16 1.2.1.79 } \\
1.2 .1 .20 \text { ] }\end{array}$ \\
\hline & K00135 & $\begin{array}{l}\text { gabD; succinate-semialdehyde dehydrogenase / glutarate- } \\
\text { semialdehyde dehydrogenase [EC:1.2.1.16 1.2.1.79 } \\
1.2 .1 .20 \text { ] }\end{array}$ \\
\hline & K00135 & $\begin{array}{l}\text { gabD; succinate-semialdehyde dehydrogenase / glutarate- } \\
\text { semialdehyde dehydrogenase [EC:1.2.1.16 1.2.1.79 } \\
1.2 .1 .20 \text { ] }\end{array}$ \\
\hline & K00135 & $\begin{array}{l}\text { gabD; succinate-semialdehyde dehydrogenase / glutarate- } \\
\text { semialdehyde dehydrogenase [EC:1.2.1.16 1.2.1.79 }\end{array}$ \\
\hline
\end{tabular}




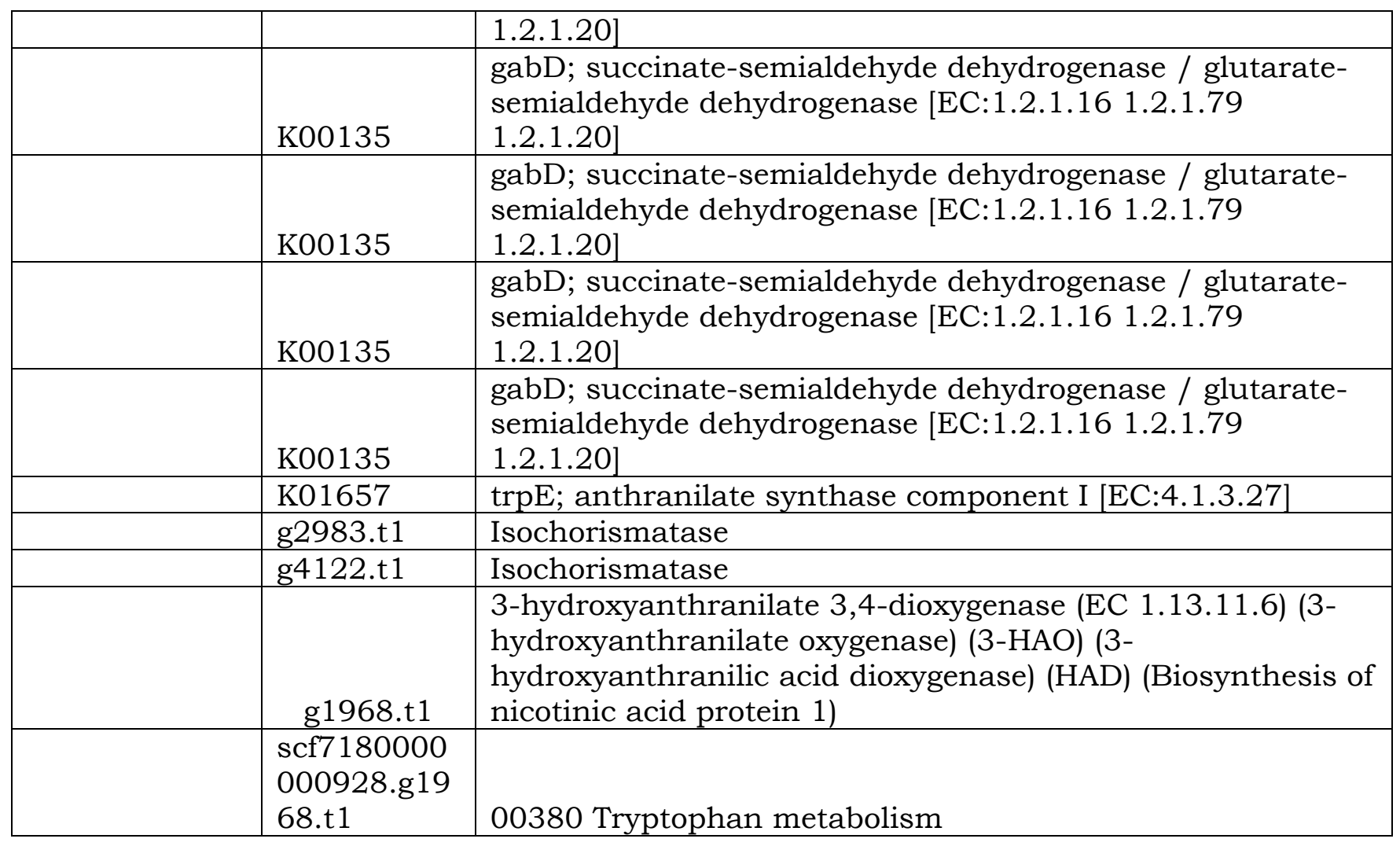




\section{Gene Ontology}

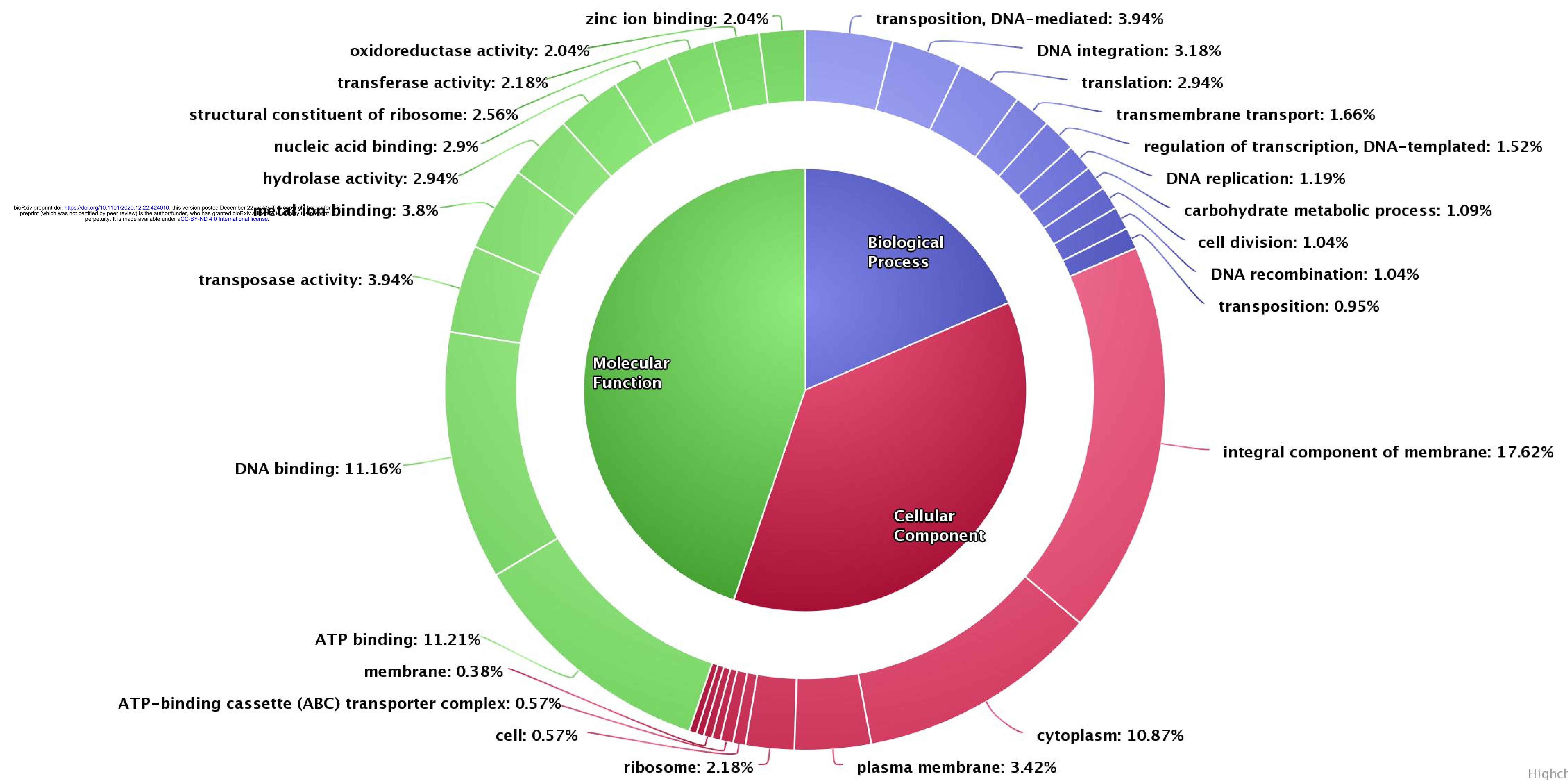




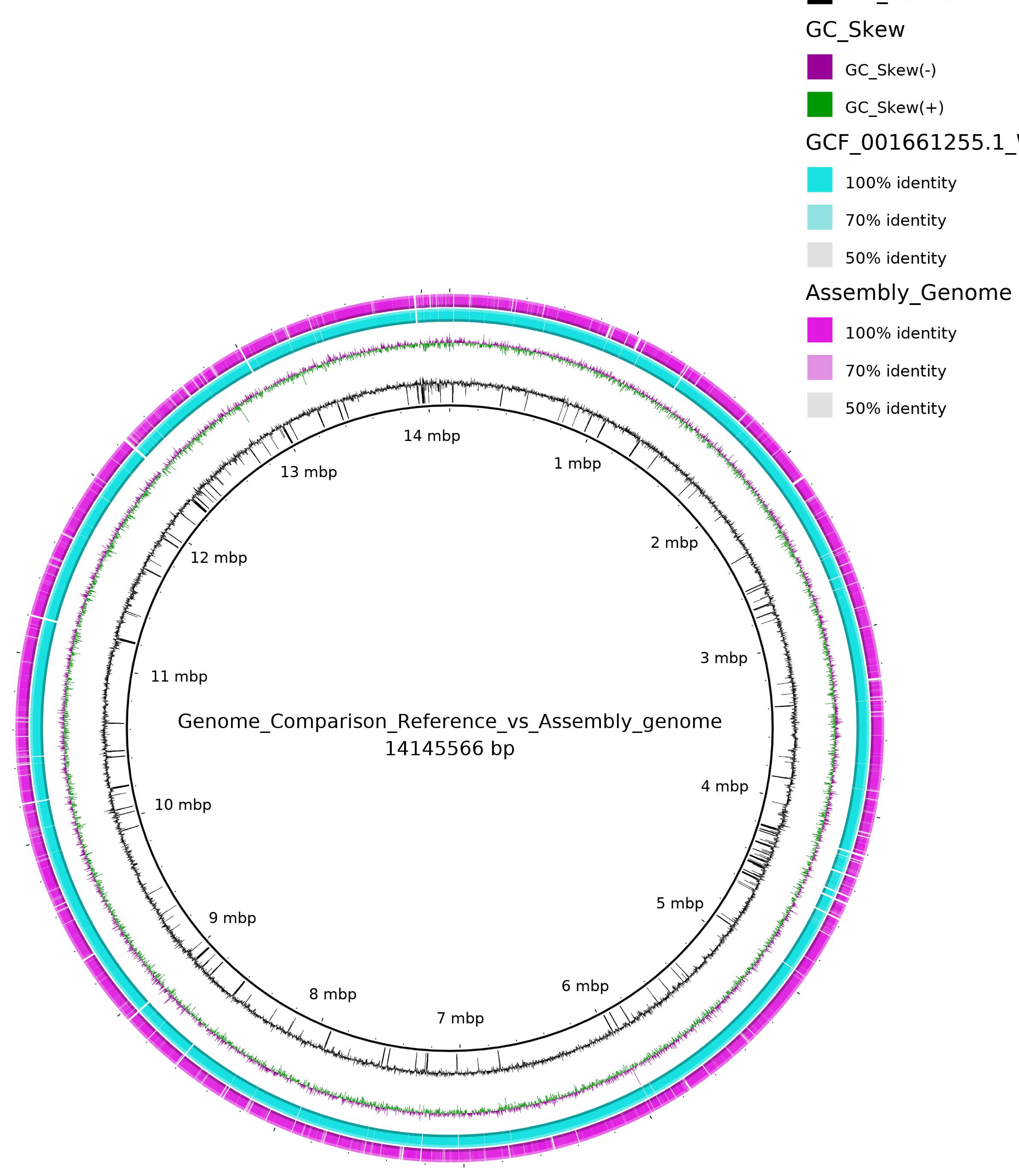




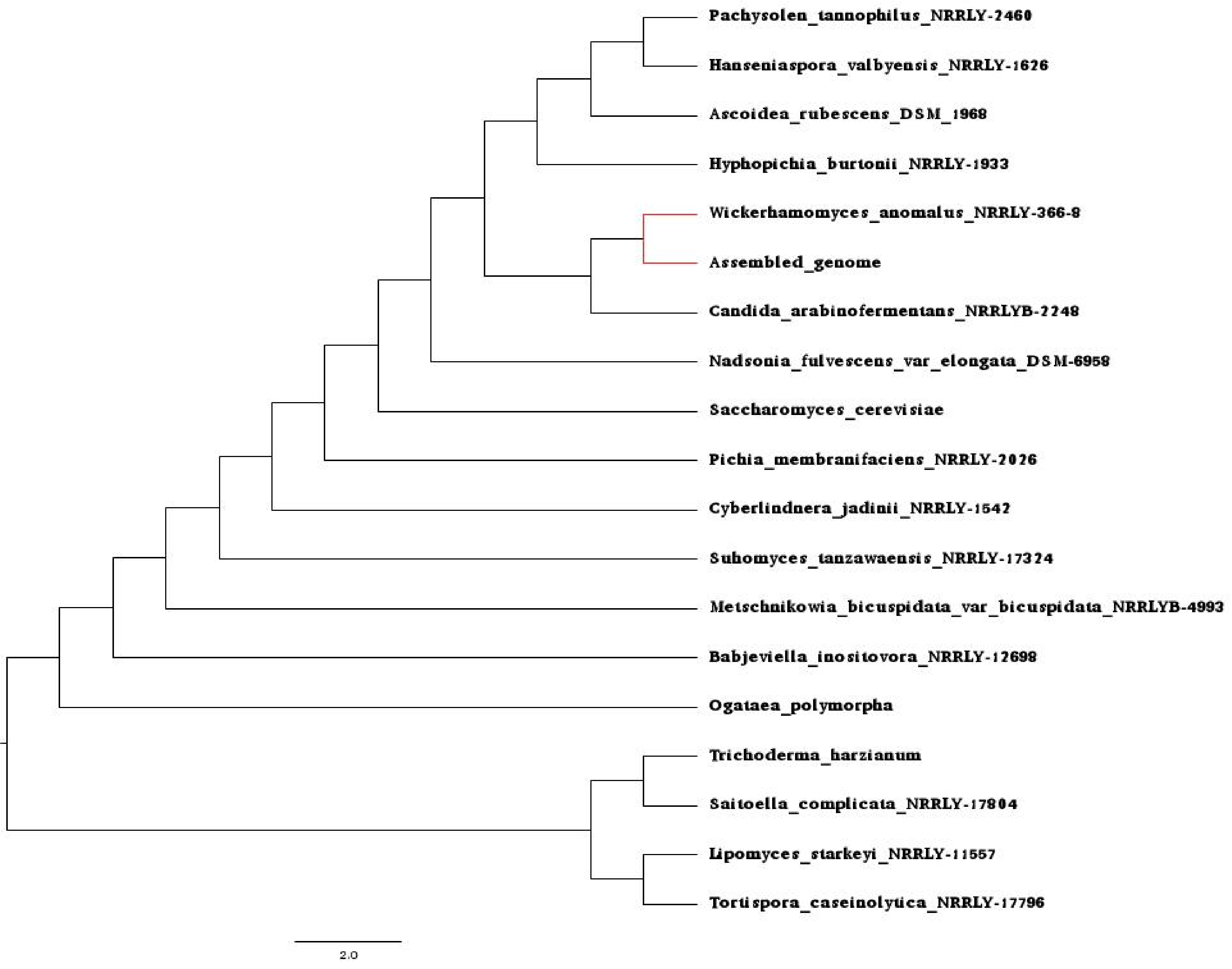




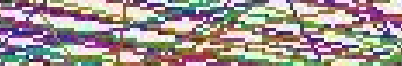

s.

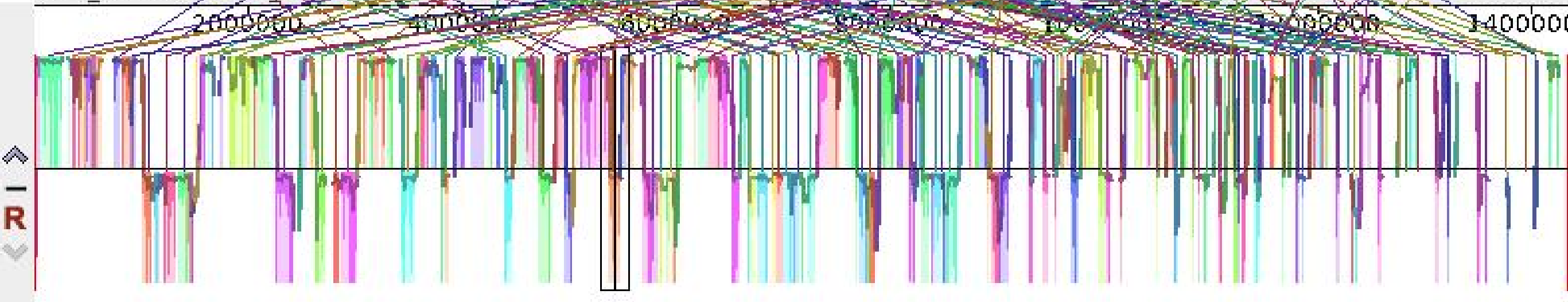




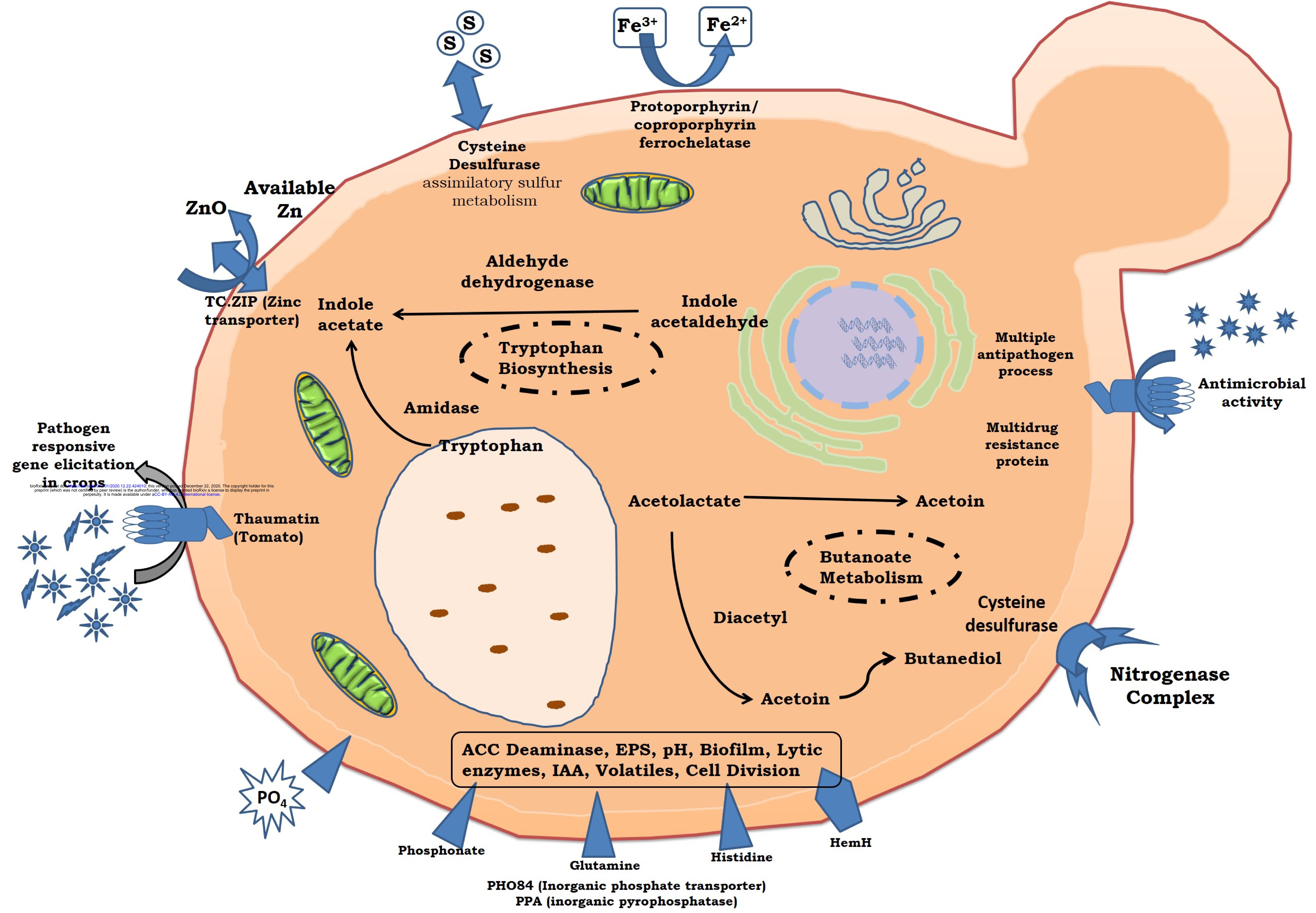

